\title{
La Colección de voces usadas en la minería, edición y estudio de un manuscrito anónimo del siglo XIX ${ }^{1}$
}

\author{
Pilar Díez de Revenga Torres \\ Miguel Ángel Puche Lorenzo \\ Universidad de Murcia
}

\section{INTRODUCCIÓN}

El texto que nos ocupa y que reproducimos a continuación es un vocabulario incompleto e inédito de voces de la minería, manuscrito que se encuentra en la Biblioteca Histórica de la E.T.S.I. de Minas de Madrid²; el manuscrito mide $21.4 \mathrm{~cm}$. por $15.7 \mathrm{~cm}$., sin encuadernación, y se compone de 124 páginas escritas en papel más algunas en blanco. Tampoco consta la fecha, aunque en la ficha bibliográfica se incluye 1810 como dudosa. Está registrado como Colección de voces usadas en la minería, aunque en el original la última palabra se halla oculta bajo una etiqueta de clasificación bibliográfica, en la que consta la signatura 20-5-46 que no es la actual. Se atribuye la autoría a J. Javalcón, pero el autor no figura en ninguna parte, ni al principio ni al final; observando el manuscrito advertimos que se ha tomado la primera voz, que no define, como si fuera el nombre del autor, Abarcón (v. Javalcón).

En el volumen que editó Maffei (1997 [1877]), con motivo del centenario de la Escuela de Minas de España, no figura este nombre ni entre los profesores ni entre los alumnos. Solo sabemos que Jabalcón es un topónimo granadino o, también, un término propio de la carpintería (Terreros y Pando 1787, s. v. jabalcón) ${ }^{3}$, mientras que abarcón es "un aro de hierro, que en los coches sirve para afianzar la lanza dentro de la punta de la tixera, y porque la abarca y abraza se llama assi" ( $D A$ 1726, s. v. abarcón).

1 Este trabajo se ha realizado en el marco del proyecto El léxico especializado del español: la minería en Murcia en el siglo XIX, PB/16/FS/02, financiado por la Fundación Séneca de la Comunidad Autónoma de Murcia. Relacionados con este mismo proyecto, se han publicado Díez de Revenga Torres (2003, 2004 y en prensa) y Puche Lorenzo (2002-2003, 2004 y en prensa).

2 Biblioteca Histórica de la E.T.S.I. de Minas de Madrid, Signatura 622 (038) JAV. DESP. Agradecemos al personal de esta biblioteca la amabilidad con que atendió nuestras peticiones.

3 Citamos los distintos diccionarios académicos por Real Academia Española (2000). 
A la vista de lo anterior, consideramos que se trata de una obra anónima, incompleta como señalábamos, escrita en borrador con numerosas interpolaciones y abundantes tachones que, a menudo, dificultan la lectura y con el orden alfabético visiblemente alterado, de lo que fue consciente su autor ya que ocasionalmente lo apunta: Aguas (v. antes aguijón y aguilón), aguijón (aquí incluye la definición), aguilón (con su definición), etc. Al contrario, la mayoría de las veces no lo corrige: almohazar, alma de un arco, aludel; amenazar, amatista, etc; a continuación de la $\mathrm{CH}$, incluye la $\mathrm{D}$, lo que es lógico, pero ya no lo es tanto que, tras una relación de voces, avise que comienza esta letra. Cuando la concluye, inserta otras correspondientes a C, D, E, F, y J y seguidamente una sola palabra de la F.

Para editar este vocabulario hemos decidido modernizar la puntuación y la acentuación porque no se corresponden con ninguna norma de la época y tampoco son sistemáticas; así mismo, utilizar las actuales puede resultar de ayuda para comprender con mayor precisión y evitar la homofonía o las construcciones sintácticas incorrectas en las definiciones. Por el contrario, respetamos la ortografía original, aun teniendo en cuenta que en aquella época reinaba un caos absoluto porque hasta 1800 ningún sistema gozó de aceptación; es a partir de 1844 cuando las normas de la Real Academia obtienen un respaldo oficial ${ }^{4}$. Dicho caos se refleja en la frecuente confusión de $b$ y $v$, que la Real Academia aconsejaba distinguir desde el siglo XVIII; es a partir de 1852 cuando afirma que se pronuncian igual, pero se conserva el uso de ambos grafemas: vomba, cuvetas, crivón, criva, valdeses, entivar, entivación, vituminosa, varato, aprovó, destravar, bálbula, bajillas, embasijar, bara, sirbe, trabieso, etc.

Respecto a la $h$, observamos una gran arbitrariedad ya que el autor no respeta las normas que se habían dictado en 1741, según las cuales debían escribirla en todas aquellas palabras que la llevaran en latín o hubieran tenido F-, así como en sus compuestos; en desacerla, undirse, uracanes, ematites, ojadelata, enchir, astial o almodillas prescinde de ella, mientras que en holor, hoyas [ollas], etc., la emplea aunque no le corresponda.

El fonema velar fricativo sordo, / $\mathrm{x}$ /, una vez eliminado el grafema $x$ para su representación en la Ortografía de 1815, alterna en la escritura como $g$ y $j$ y así vemos: Ejipto, jemales, recojer, recojen, injenieros, ajena, ejerzitan, parage, empuge, etc.

En estremo, estremidades, espuestas, escava, escavación, estinguir, estender, estensión, esterior, esperimentan, espone, estraer, esterminio, esprofeso, etc., correspondía $x$, con valor de [ks] y, al contrario que en los ejemplos anteriores, la Real Academia sí había permitido que se escribieran con $s$ desde que se publicara la octava edición de la Ortografía en 1815, opinión que rectificó en 1844.

4 Esteve Serrano (1982: 14; para las restantes cuestiones ortográficas, vid. pp. 170-172; 304-305 y 247249 respectivamente). 
Respecto a los conocimientos de gramática, los planes de estudio de la Escuela de Minas fueron cambiando a lo largo de los años; si en 1836 se incluía en ellos la enseñanza y estudio de la lengua y la literatura española, años más tarde, en 1846, se exigía haber cursado gramática castellana que debía ser probado mediante una certificación para el ingreso en la Escuela. De la misma manera, en función del plan de enseñanza, se exigía el aprendizaje o el conocimiento de otro idioma: alemán, francés o inglés, dependiendo de los años. Este planteamiento había sido habitual desde que se sistematiza el estudio de las disciplinas necesarias para dominar el Arte de Minas, primero en la Real Sociedad Vascongada de Amigos del País y más tarde en el Real Instituto Asturiano o la Academia de Minas de Almadén, en el siglo XVIII. Para establecer la Escuela Politécnica en Madrid, las Cortes del 29 de junio de 1821 decretaron el Reglamento General de Instrucción Pública, en el que se exigía para el ingreso dominar la gramática castellana y la lengua latina, entre otras materias (Maffei 1997 [1877]: 2-44).

\section{ESTUDIO LÉXICO}

La Colección de voces usadas en la minería es un vocabulario incompleto que contiene en total 778 voces; algunas están tachadas y otras sin definir, especialmente a partir de la D.

Los términos recogidos pertenecen, por lo general, a la lengua común aunque su significado se restringe a las actividades propias de la minería como, por ejemplo, acequia o crucero, y no hay entre ellos tecnicismos extranjeros, salvo cuando se denomina algún mineral: amianto, antimonio o cinabrio, conocidos desde antiguo, junto a otros que se habían descubierto recientemente, como belemnita o blenda.

El autor organizó esta obra sin tener en cuenta ningún criterio lexicográfico, desde el orden alfabético al que hacíamos referencia hasta el género y el número, incluyendo indistintamente las voces en masculino o femenino, en singular o plural, con la excepción de apuradoras o dores: las o los que tienen el oficio de apurar, que extiende la diversidad de género no solo al lema sino también a la definición, adelantándose más de un siglo a lo que, en la actualidad, es políticamente correcto y atenta contra los principios básicos de la lengua española.

Mezcla indiscriminadamente sustantivos, adjetivos o verbos con palabras compuestas: bocamejora, contramina, bancos de arena, barreno de flor, cabestrillo de sierra, frases hechas: abrir mina sobre tierra muerta, arrear las mulas o caballos, cuartear un contrato, denunciar mina, construcciones sintagmáticas en las que el segundo elemento que las forma restringe al ámbito de la minería, o actividades vinculadas a ella, la extensión significativa del primer término: arena metalifera, arrimadores de mineral, candil de mina, cargo de mineral, compañia de mineros, chimenea del atizadero, espetón de horno, etc., así como otras expresiones: ahí es arriba, ahi es abajo, etc. 
En términos generales, la obra carece de marcación diatécnica ${ }^{5}$. Respecto a la información diatópica, si la incluye, lo hace al final de la definición como Voz amer, aunque integrada en ella sí puede aludir a que es característica de Almadén, Nueva España, América, etc.: Azoguería= En Nueva España, la oficina donde se incorpora el azogue; Carros de mano= En Almadén, especie de parigüelas que tienen una rueda en un estremo en medio de los dos largueros; Chupalla= Es una medida de que se usa en América para el azogue [...], o que el objeto definido se utiliza en esos lugares. Éste es el mismo procedimiento que utiliza con la información etimológica: Almadén= En árabe significa la mina, voz compuesta del artículo al y el sustantivo maden; Bantrote= Palabra tomada de la alemana wandtruhe.

En el vocabulario que nos ocupa, el autor frecuentemente nos proporciona datos diafásicos de algunos de los términos que incluye, relacionados con la minería generalmente: Azolbarse = voz usada entre los mineros; Boqueta $=$ Se llama en la minería $[. .$.$] ; Bóveda =$ Se llama en las minas [...]; Brocal= Llámanse en las minas [...]; Empalmar $=$ En las minas se dice [...] o, en menor proporción, con otras actividades: Calda $=$ Llaman los herreros... En otras ocasiones, nos indica que la voz es común a cualquiera de ellas: Buena construcción= Voz general que se aplica $[\ldots]$.

La información gramatical no solo no es sistemática, sino que es escasa. Se localiza en términos como acequiado, adj.; acodalado, part. pas.; acoplado, part. pas.; asarmelado, part. pas. y cazumbrado, par. pas. En ocasiones, la categoría gramatical se explica en la definición: Amenazar ruina un hastial= Frase que se usa [...], pero no siempre acierta en la clasificación, como sucede en Ahi es arriba= Es preposición que usan los mineros [...]. Algunas veces juzga el autor la pertinencia del significado: Bolas de bacisco= Nombre impropio que se da en Almadén [...] y otras recurre a ciertas expresiones para confirmar un matiz determinado: Boca$z o=[. .$.$] y entonces se dice "ha dado bocazo"; Bofetón= Se dice que se da de bo-$ fetón cuando [...].

El interés por recopilar términos específicos de la minería en diccionarios y vocabularios no era nuevo, ya que se conocen en los siglos anteriores antecedentes tanto en América, donde apareció el Diccionario y maneras de hablar que se usan en las minas... de García de Llanos (1983 [1609]), como en España, con el Diccionario. Índice... de José Parés y Franqués $(1785)^{6}$. Las diferencias entre estas dos obras y la que ahora editamos son notables; aunque existen voces comunes, el planteamiento de la definición es diferente debido, sin duda, a la distancia en el espacio y en el tiempo, lo que influyó en las lógicas modificaciones en la actividad

5 Sobre este tema se puede consultar Garriga Escribano (1994, 1998, 1999, 2001, 2003 y 2004).

6 Una selección de las voces fue editada por Menéndez Navarro (1995); actualmente, preparamos una edición del diccionario completo. 
desarrollada, debido al avance de la técnica y a los distintos procedimientos de trabajo en las correspondientes cuencas.

Con posterioridad, en 1848, se edita el Diccionario de las voces más usadas en minería ${ }^{7}$, que igualmente presenta diferencias con la Colección que nos ocupa, si bien no son tan acentuadas como las anteriores en lo que se refiere a las definiciones, dado que era más cercano en el tiempo. No obstante, sí divergen en el número de entradas, ya que la Colección es incompleta, pero, si comparamos la A, ésta resulta ser mucho más rica que aquél desde el punto de vista léxico.

\begin{tabular}{|c|c|c|}
\hline VoCES & \multicolumn{1}{|c|}{ GARCÍA DE LLANOS } & \multicolumn{1}{c|}{ ANÓNIMO, S. XIX } \\
\hline azoguero & $\begin{array}{l}\text { Dícense así los que tienen ingenios en } \\
\text { Potosí por el azogue del beneficio. } \\
\text { Dirase mas en la palabra soldados. }\end{array}$ & $\begin{array}{l}\text { En Nueva España el que tiene por ofi- } \\
\text { cio el incorporar el azogue, sal y ma- } \\
\text { gistral, en los montones de la mina } \\
\text { molida de la plata para el beneficio de } \\
\text { este metal. }\end{array}$ \\
\hline criadero & $\begin{array}{l}\text { Dícense así las minas que tienen su ri- } \\
\text { queza en la superficie a manera de } \\
\text { bolsas y no forman vetas, y si las for- } \\
\text { man no van seguidas al centro, antes } \\
\text { se acaban luego de golpe, en lo cual } \\
\text { se ve cuan diferentes sean de las vetas } \\
\text { que van a bolsas, las cuales de ordina- } \\
\text { rio vuelven aunque se pierdan. }\end{array}$ & $\begin{array}{l}\text { Especie de bolsa o bóveda en que el } \\
\text { metal está suelto. Llámase también } \\
\text { bohedal. }\end{array}$ \\
\hline chiflón, a & $\begin{array}{l}\text { Es cierta manera de labrar que se dirá } \\
\text { en la palabra labrar. }\end{array}$ & $\begin{array}{l}\text { Se dice cuando a un tiempo se gana } \\
\text { en la mina longitud y profundidad. }\end{array}$ \\
\hline
\end{tabular}

7 Este diccionario ha sido estudiado, con un enfoque dialectal, por Ahumada (2000) y por Díez de Revenga Torres y Puche Lorenzo desde la perspectiva de la lexicografía de especialidad (en prensa). 


\begin{tabular}{|c|c|c|}
\hline VOCES & PARÉS Y FRANQUÉS & ANÓNIMO, S. XIX \\
\hline alcayata & $\begin{array}{l}\text { Es un clavo de hierro de una tercia de } \\
\text { largo poco mas o menos y de un dedo } \\
\text { de grueso con un gancho a su princi- } \\
\text { pio. Sirve para colgar de ellos la esca- } \\
\text { leras [sic] o cualquiera otra cosa. Cla- } \\
\text { vus uncatus. }\end{array}$ & $\begin{array}{l}\text { Clavo de hierro de cuya cabeza sale } \\
\text { una especie de codillo que sirve para } \\
\text { tender lo que se cuelga en el y tam- } \\
\text { bien para asegurar las escaleras ya sea } \\
\text { en las piedras o en algunas planchas } \\
\text { de los descansillos que hay en las mi- } \\
\text { nas entre una y otra escalera. }\end{array}$ \\
\hline atacadera & $\begin{array}{l}\text { Vaqueta o vara semicircular de hierro } \\
\text { para atacar los barrenos despues de } \\
\text { cargados y puesta aguja. Frudiculus } \\
\text { semicircularis. Vid. Barreno. Atacade- } \\
\text { ra de cargar. }\end{array}$ & $\begin{array}{l}\text { Instrumento de hierro que sirve para } \\
\text { atacar el barreno; no debe tener nada } \\
\text { de aceros porque no haga chispas an- } \\
\text { tes de tiemo [sic]: en algunas partes } \\
\text { suelen ser de madera dura, y son mas } \\
\text { seguros aunque duren poco tiempo. }\end{array}$ \\
\hline boliches & Subicus terreus. Vid. Barreno. & $\begin{array}{l}\text { Cilindritos que se hacen con barro en- } \\
\text { carnado como de unas } 4 \text { pulgadas de } \\
\text { largo y ? de grueso que sirven ó se } \\
\text { emplean en atacar los barrenos: y } \\
\text { también el lodarlos cuando destilan } \\
\text { agua. }\end{array}$ \\
\hline buje & $\begin{array}{l}\text { Armadura de hierro, que tienen las } \\
\text { ruedas de los carritos de mina inte- } \\
\text { rior-mente, por donde juega el ege, } \\
\text { para que este no las gaste tanto. Cir- } \\
\text { culus ferreus, rota interius fixus, } \\
\text { aximque tangens. }\end{array}$ & $\begin{array}{l}\text { La rodaja de hierro con que se calza } \\
\text { interiormente la boca de los cubos de } \\
\text { la ruedas de las carretas para que no } \\
\text { luda contra el eje. }\end{array}$ \\
\hline
\end{tabular}




\begin{tabular}{|c|l|l|}
\hline \multicolumn{1}{|c|}{ VOCES } & ANÓNIMO. MANUSCRITO, S. XIX & \multicolumn{1}{|c|}{ ANÓNIMO, 1848 } \\
\hline ademar & $\begin{array}{l}\text { Es forrar y cubrir los postes pilares o } \\
\text { llaves aunque sean de metal riquísi- } \\
\text { mo, con maderaje para conservarlos y } \\
\text { evitar que los mineros los destruyan } \\
\text { para hurtar el metal, o no se pongan } \\
\text { ellos mismos en peligro de perder la } \\
\text { vida. Voz amer. }\end{array}$ & $\begin{array}{l}\text { Entivar, fortificar con adémas, forrar } \\
\text { ó cervacion (América). }\end{array}$ \\
\hline buitron & $\begin{array}{l}\text { Es un sitio largo, solado, parejo donde } \\
\text { se ponen los cuerpos o cajones para } \\
\text { beneficiar el mineral. }\end{array}$ & $\begin{array}{l}\text { El hogar de los hornos reverberos. } \\
\text { (Linares.) Horno de manga para la } \\
\text { fundicion de minerales argentíferos. } \\
\text { (América). }\end{array}$ \\
\hline caballo & $\begin{array}{l}\text { Dureza de piedra firme que se nota al } \\
\text { labrar tiro o caña. }\end{array}$ & $\begin{array}{l}\text { Masa de roca estéril interpuesta en un } \\
\text { criadero. Especie de grua muy senci- } \\
\text { lla para levantar y trasportar grandes } \\
\text { pesos en las afinerías. (Marbella). }\end{array}$ \\
\hline
\end{tabular}

El autor de la Colección [...] era una persona que conocía la actividad minera ya que una parte considerable de las definiciones están redactadas con un alto grado de especialización, aunque la voz en cuestión pueda pertenecer a la lengua general en principio. Así vemos, por ejemplo, barra: "Instrumento de hierro calzado que sirve para palenquear las piedras que se arrancan de la mina o cantera. Las hay de varios tamaños, por lo regular suele ser de $1 \frac{1}{2}$ vara de largo y $2^{1 / 2}$ palmos de grueso, de forma cilíndrica". Así mismo, era conocedor de los nuevos descubrimientos en materia mineralógica, con toda seguridad, a través de obras extranjeras o de traducciones al español, como se aprecia en la definición de alabastriles en la que, tras la descripción del mineral, incorpora los siguientes datos: “[...] Hállase con especialidad en Alemania y también hay descubierta una bellísima cantera en las inmediaciones de París. El Sr. Poll ha hecho sobre esta piedra muchas esperiencias para poder determinar la verdadera naturaleza de la piedra de yeso".

Aun teniendo en cuenta este acervo mineralúrgico, en terminología de Maffei, nuestro autor anónimo tuvo presente en todo momento los diccionarios de la Real Academia, como lo muestran las coincidencias formales que se observan entre algunas de las definiciones de la Colección de voces usadas en la minería y el diccionario académico. La mayor parte de ellas se hacen notables a partir de la edición de 1770, sin restar importancia a un gran número de palabras que se integraban en 
la lexicografía académica desde sus inicios e, incluso, Nebrija las había recogido. No obstante, al tratarse de voces especializadas, muchos términos se incluyeron años después, principalmente en las ediciones de 1869 y 1884 y otros en época muy tardía, muy avanzado el siglo Xx, en 1989, como sucede con acople. Frente a este planteamiento, se da la circunstancia de que alguna palabra tuvo una vida efímera en la lexicografía académica, como calichal o cabeceadero que solo aparecen en la edición de 1936, aunque esta última sí fue incluida en los diccionarios de Zerolo, en 1895, y Alemany, en 1917.

No es nuestro objetivo ahora analizar la importancia que tuvo el avance de la ciencia en el siglo XIX, pero sí es de señalar que un número considerable de voces solo fueron recopiladas por lexicógrafos no académicos como, por otra parte, había sido una práctica habitual. Así ocurre con ademación (Castro y Rossi 1852), almohadillar (Zerolo 1895), angulario (Núñez 1825), asón (Gaspar y Roig 1852), bufonites (Domínguez 1853), civicón (Alemany 1917) o estopar (Sobrino 1705 y Zerolo 1895).

La riqueza de este repertorio, a pesar de recopilar voces recogidas en otros diccionarios y de recurrir a conocimientos adquiridos sobre la materia, radica en que nos proporciona un buen número de términos que no se localizaban en ninguna tradición lexicográfica, ya fuera académica o no, y que tampoco figuraban en los vocabularios técnicos que citábamos anteriormente: abuzar, acongrielar, alabastriles, alamandina, alenman, alamadenejos, alumbre de roca, amocrisis, anguijuela, antropolites, antropomorfites, arapera, atinoar, azoguera, balasa, barlete, bibliquí, boheda, borrascarse, brontia, calahuezo, calcinación linitoria, cañonaje, cazumbros, ciguiñuela ${ }^{8}$, cincho de cubatina, clavo tercial, clavo pesiero, congrieles, crivón, cux, chaleite, desclave, chavetear, dentenalla, desazolbar, embarlotar, embarlote, enarmillar, esquijerar ${ }^{9}$, emplanchar, encamador, enlatonar, ensamblamiento, entehallas, enterizo, escarbadera ${ }^{10}$ y escoplar.

Localizamos coincidencias formales entre las definiciones que incorporaron los diversos diccionarios que hemos citado y el manuscrito Colección de voces usadas en la minería. Nos ha llamado la atención cuando estas coincidencias se producen en las ediciones del $D R A E$ de la segunda mitad del siglo XIX, porque a su vez estaban ya recogidas en el Diccionario de las voces más usadas en minería de 1848. Esto nos sirve para marcar la trascendencia que tuvo el manuscrito que editamos ya que, sin haberse publicado, sirvió de base para el anónimo de 1848, y así establece-

8 La variante ceguiñuela está recogida por la Real Academia en el $D A$, en el $D R A E-1936$ y en muchos de los diccionarios no académicos del siglo XIX. En el diccionario manuscrito de Parés y Franqués aparece cigueñuela, que es la variante incorporada por la Real Academia a partir de 1803.

9 A partir del DRAE-1791 se incorpora desquijerar.

10 La forma masculina de escarbadera está recogida a partir del $D R A E-1791$, pero con un significado que nada tiene que ver con la minería. 
mos la relación entre el manuscrito y el anónimo, basándonos en que el primero parece ser un trabajo de clase, que no se concluyó y que se conserva en la Escuela de Minas, y el segundo probablemente fue redactado en esa misma escuela por F. Naranjo y Garza o bajo su supervisión (Díez de Revenga Torres y Puche Lorenzo, en prensa), y fue consultado por los redactores del diccionario académico de los años 1869,1884 y 1899 y por otros lexicógrafos como Zerolo. Estaba, pues, integrado en la tradición lexicográfica porque el autor consultó diccionarios anteriores, pero también influyó en los posteriores.

A continuación adjuntamos un cuadro con el fin de poder observar con mayor claridad estas cuestiones:

\begin{tabular}{|c|c|c|}
\hline VoCES & & DICCIONARIOS \\
\hline \multirow[t]{2}{*}{ ademes } & Colección & $\begin{array}{l}\text { Cubiertas o forros de madera con que se aseguran y } \\
\text { resguardan los tiros, pilares y labores. Voz amer. }\end{array}$ \\
\hline & $D R A E-1770$ & $\begin{array}{l}\text { La cubierta ó forro de madera con que se aseguran, y } \\
\text { resguardan los tiros, pilares, y labores de las Minas [...]. }\end{array}$ \\
\hline \multirow[t]{2}{*}{ almohaza } & Colección & $\begin{array}{l}\text { Instrumento de hierro con que se estrega a las caballerías para } \\
\text { sacarles la caspa que crían y el polvo que recojen entre el } \\
\text { pelo. Compónese de una chapa de hierro con } 4 \text { o } 5 \text { serrezuelas } \\
\text { de dientes menudos y romos. }\end{array}$ \\
\hline & $D R A E-1770$ & $\begin{array}{l}\text { Instrumento de hierro con que se estrega á las caballerias para } \\
\text { sacarlas la caspa que crian, y el polvo que recogen entre el } \\
\text { pelo: compónese de una chapa de hierro con quatro ó cinco } \\
\text { serrezuelas de dientes menudos y romos, y de un mango de } \\
\text { madera con que se maneja [...]. }\end{array}$ \\
\hline \multirow[t]{2}{*}{ alúmina } & Colección & $\begin{array}{l}\text { Tierra muy suave y untuosa al tacto, más o menos blanca } \\
\text { según su pureza, que se pega a la lengua y despide un olor } \\
\text { térreo particularmente cuando se moja. }\end{array}$ \\
\hline & $D R A E-1817$ & $\begin{array}{l}\text { Tierra muy suave y untuosa al tacto, mas ó menos blanca } \\
\text { segun su pureza, sin sabor determinado, y que se pega á la } \\
\text { lengua y al paladar. Puesta en agua la absorbe y despide un } \\
\text { olor térreo particular [...]. }\end{array}$ \\
\hline
\end{tabular}




\begin{tabular}{|c|c|c|}
\hline \multirow[t]{2}{*}{ bermellón } & Colección & $\begin{array}{l}\text { Fósil que se compone de azogue y azufre. Es sumamente } \\
\text { pesado, de un hermoso color rojo y de grande uso en las artes. } \\
\text { En Almadén se fabrica desde que el famoso D. Diego de } \\
\text { Larrañaga descubrió su elaboración después de un viaje a } \\
\text { Alemania por el Gobierno. }\end{array}$ \\
\hline & $D R A E-1817$ & $\begin{array}{l}\text { Fosil que se compone de azufre y azogue. Es sumamente } \\
\text { pesado, de un hermoso color rojo, y de grande uso en las artes: } \\
\text { bien que todo el que se emplea en ellas es artificial. }\end{array}$ \\
\hline \multirow[t]{2}{*}{ buje } & Colección & $\begin{array}{l}\text { La rodaja de hierro con que se calza interiormente la boca de } \\
\text { los cubos de las ruedas de las carretas para que no luda contra } \\
\text { el eje. }\end{array}$ \\
\hline & $D R A E-1843$ & $\begin{array}{l}\text { La rodaja de hierro con que se calza interiormente la boca de } \\
\text { los cubos de las ruedas de los coches ó carros, para que no } \\
\text { luda contra el eje. }\end{array}$ \\
\hline \multirow[t]{3}{*}{ ahonde } & Colección & $\begin{array}{l}\text { El fondo que los mineros de América deben dar a las minas en } \\
\text { el término de tres meses, sin lo cual no se les debe dar la } \\
\text { posesión de ellas; este es cuando menos de } 5 \text { varas de ancho, } 6 \\
\text { de largo y } 7 \text { de profundo [...]. }\end{array}$ \\
\hline & Anón., 1848 & $\begin{array}{l}\text { DE UNA MINA: la profundidad determinada de siete varas en } \\
\text { tres meses que se da á las de América para obtener la } \\
\text { propiedad y posesión. [...]. }\end{array}$ \\
\hline & $D R A E-1884$ & $\begin{array}{l}\text { Profundidad de siete varas que en América se había de dar en } \\
\text { tres meses á la mina, para obtener su propiedad. }\end{array}$ \\
\hline \multirow[t]{3}{*}{$\begin{array}{l}\text { buzar } \\
\text { (el filón) }\end{array}$} & Colección & $\begin{array}{l}\text { Es cuando éste se inclina a una u otra parte; y así se dice buza } \\
\text { a P.L. \& cuando su inclinación es a P.L. \&. }\end{array}$ \\
\hline & Anón., 1848 & Inclinar ó tener buzamiento. \\
\hline & $D R A E-1884$ & Inclinarse hacia abajo los filones metalíferos. \\
\hline \multirow[t]{2}{*}{ cascujo } & Colección & Zafra mala de todas clases. \\
\hline & Anón., 1848 & $\begin{array}{l}\text { Zafra completamente esteril en pequeños fragmentos. } \\
\text { (Almaden). }\end{array}$ \\
\hline
\end{tabular}




\begin{tabular}{|l|l|l|}
\hline \multirow{3}{*}{ despilar } & Zerolo, 1895 & $\begin{array}{l}\text { Zafra completamente estéril en pequeños fragmentos. Dícese } \\
\text { en Almadén. }\end{array}$ \\
\cline { 2 - 3 } & Anón.,1848 & Quitar o echar abajo los pilares en las minas. \\
\cline { 2 - 3 } & DRAE-1884 & Derribar los pilares de una mina. \\
\hline
\end{tabular}

\section{CONCLUSIONES}

Para poner de manifiesto la importancia de este tipo de obras para la lexicografía y la historia del léxico técnico del español, retomamos la afirmación de Menéndez Navarro al considerar, con respecto al Diccionario de Parés y Franqués, que "podría enmarcarse más propiamente en la corriente de casticismo del siglo XVIII: la reivindicación de una ciencia o de una lengua propias frente al peso creciente de corrientes extranjeras. Corrientes que desconocían las "realidades locales". Así, la riqueza de vocablos propios harían innecesario el recurso a términos técnicos extranjeros, sin renunciar por ello a algunos préstamos" (1995). Aunque el diccionario anónimo que ahora editamos pertenece al siglo XIX y en él apenas se localizan préstamos de lenguas extranjeras, como sucede en la obra de Parés y Franqués, pensamos que esta circunstancia no se inscribe necesariamente en la corriente casticista del idioma, sino más bien en el propio devenir de una actividad tradicional que arrastraba, desde los albores del idioma, un léxico propio que la describía. De hecho, en las Partidas podemos leer: "Fundiendo algún onbre oro o plata o otro metal alleno, mesclándolo con otro so sin plazer de aquel cuyo es e faziendo dello masa o [vergas] en salvo, finque el señorío al otro cuyo era en aquello que así fose ajuntado con lo suyo..."

A partir principalmente de la segunda mitad del siglo XIX esta situación empieza a variar de forma notable, pues los avances tecnológicos, que hasta ese momento habían llegado a la lengua española y repercutido en ella tímidamente, entran a raudales. Por ello, no es de extrañar que en los diccionarios especializados que hemos citado se recurra constantemente a las variantes diatópicas de la terminología minera, como principal información.

A partir de nuestro estudio hemos comprobado cómo la Colección de voces usadas en la minería se encuentra inserta dentro de la tradición lexicográfica decimonónica, recibiendo destacadas influencias y dejando su impronta en diccionarios posteriores a su redacción. En consecuencia, y a pesar de ser un texto manuscrito y 
sin fechar, podemos afirmar que fue redactado en el seno de la Escuela de Minas después del año 1843, puesto que hasta esa fecha hemos advertido que en algunas definiciones aún se nutre del DRAE. Del mismo modo, tras conocer la existencia del diccionario de 1848, dirigido o redactado, con toda probabilidad, por Naranjo y Garza, no resulta difícil considerar que la colección que aquí presentamos fuera un trabajo elaborado por algún alumno de la Escuela y, por tanto, una posible colaboración para aquél.

Lamentablemente, la colección se halla incompleta, pero aun así resulta de un enorme valor al permitirnos conocer una parte del léxico de la minería a través de alguien formado y vinculado a esta actividad. 


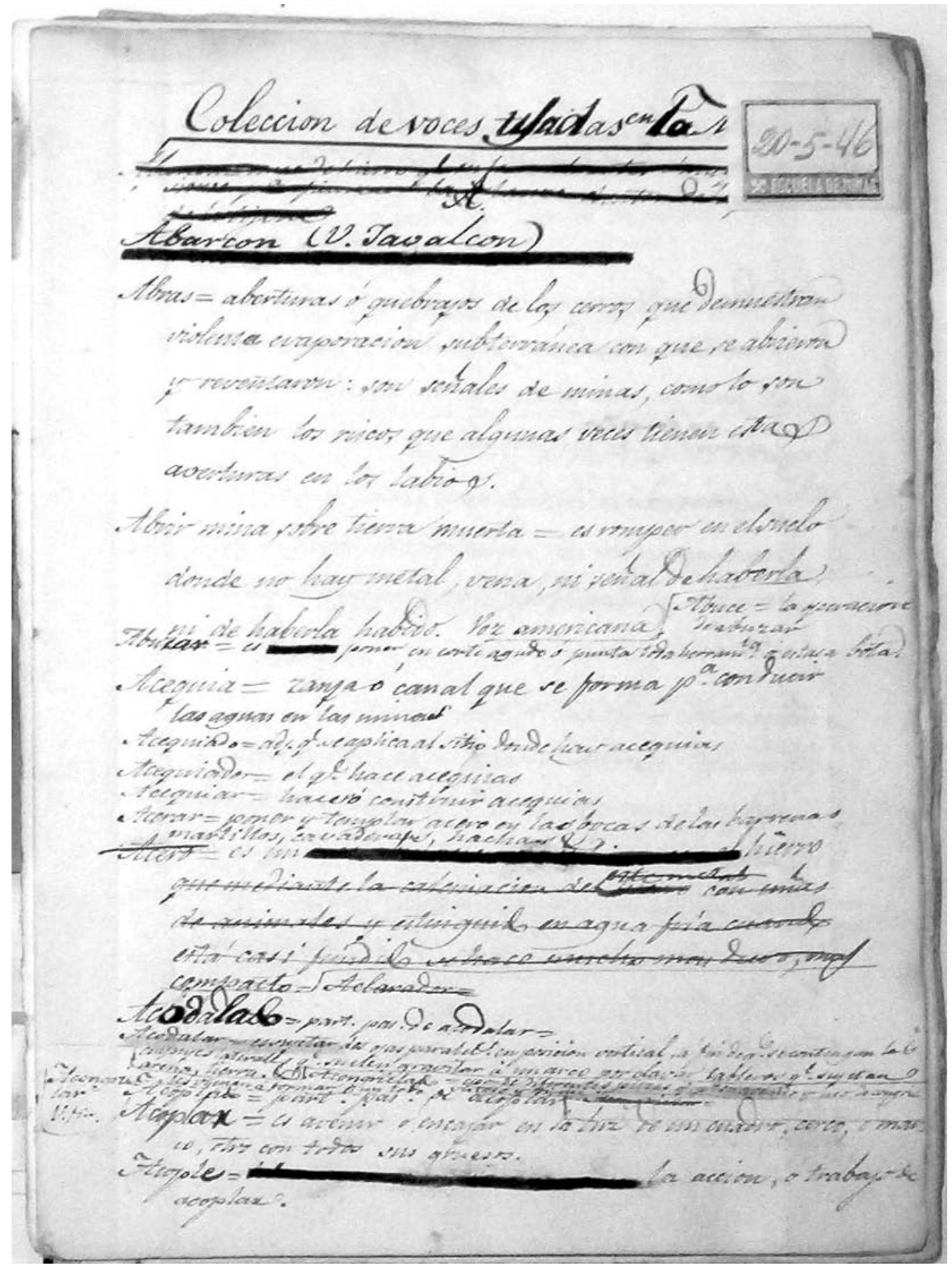

Colección de voces usadas en la minería, $f .1 r$. 


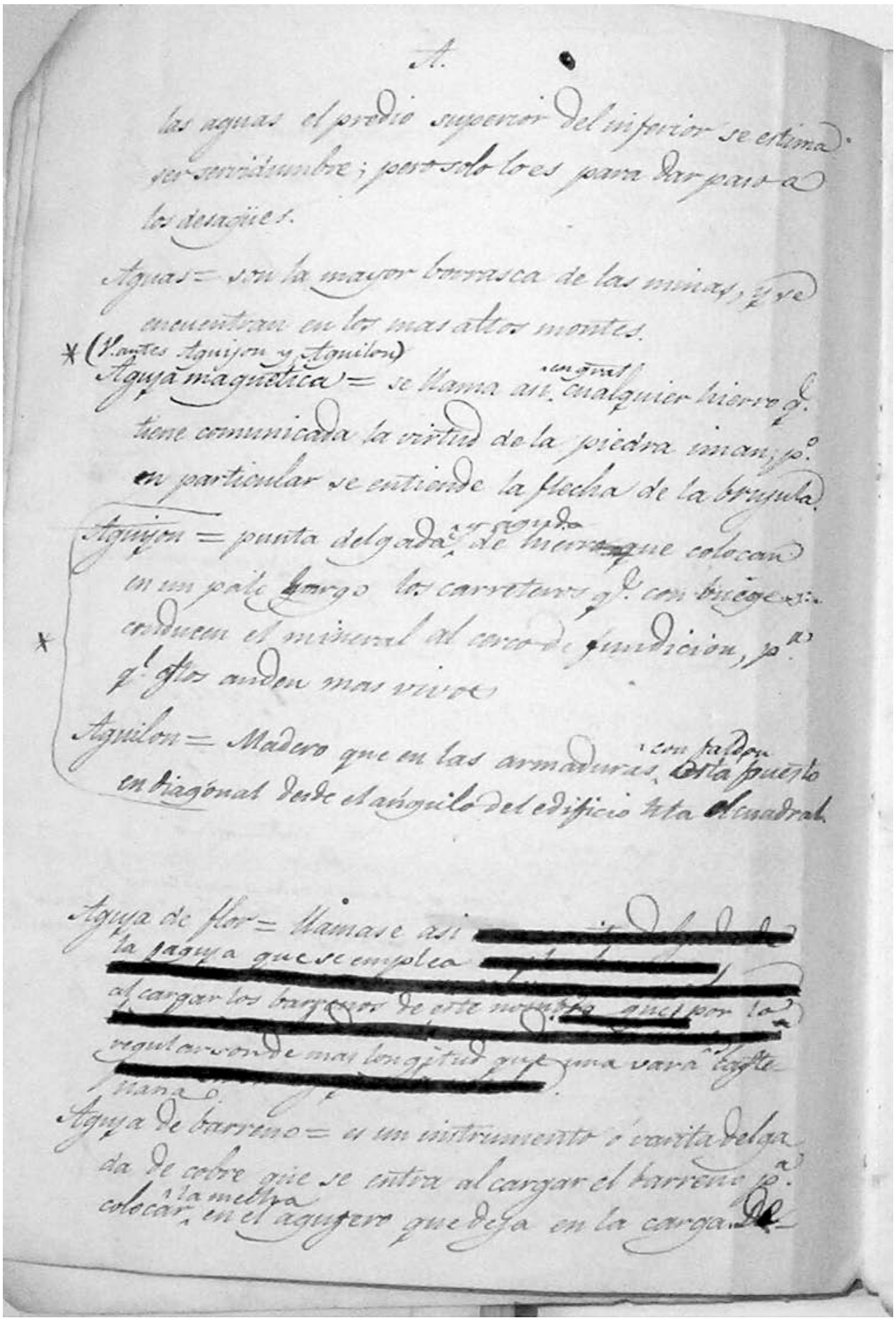

Colección de voces usadas en la minería, $f .4 v$. 


\section{REFERENCIAS BIBLIOGRÁFICAS}

AhUmAdA, Ignacio (2000): "El español de Jaén. Revisión bibliográfica (1848-2000)", Senda de los Huertos, 57-60, pp. 403-428.

Diccionario de las voces más usadas en minería (1848), Madrid, Imprenta de D. Antonio Yenes.

Díez de Revenga Torres, Pilar (2003): "Lengua poética y lengua técnica: creación y ciencia", ELUA, Estudios de Lingüistica de la Universidad de Alicante, 17, pp. 263-272.

_ (2004): “El color de los minerales, ¿cuestión lingüística o técnica?”, Revista de Investigación Lingüistica, vII, pp. 91-104.

— (en prensa): "En busca de una terminología: el léxico minero del siglo XIX”, en Actas del XVI Congreso de Lingüistica General

— y Miguel Ángel Puche Lorenzo (en prensa): "Los repertorios lexicográficos técnicos del siglo XIX: la difusión de la minería" en M. Campos, R. Cotelo y J. I. Pérez Pascual, eds., Historia del léxico español, A Coruña, Universidade da Coruña.

EsteVe SerRano, Abraham (1982): Estudios de teoría ortográfica del español, Murcia, Universidad de Murcia.

GARriga Escribano, Cecilio (1994): "La marca de "vulgar" en el DRAE: de Autoridades a 1992", Sintagma, 6, pp. 5-13.

- (1998): Las marcas de uso en el Diccionario de la Academia: evolución y estado actual, Tarragona, Universidad Rovira i Virgili.

— (1999): "El registro familiar como marca lexicográfica", en P. Díez de Revenga y J. M. Jiménez Cano, eds., Estudios de sociolingüística II, Murcia, DM, pp. 141-172.

(2001): "Sobre el Diccionario académico: la 12a ed. (1884)", en A. M. Medina Guerra, coord., Estudios de lexicografía diacrónica del español, Málaga, Universidad de Málaga, pp. 261-315.

- (2003): "La microestructura del diccionario: las informaciones lexicográficas", en A. M. Medina Guerra, coord., Lexicografía española, Barcelona, Ariel, pp. 103-126.

(2004): "Lengua y ciencia en español: reflexiones lingüísticas de los científicos en los siglos XVIII y XIX”, en M. T. Cabré y R. Estopà, coord., Objetividad cientifica y lengua, Barcelona, Universitat Pompeu Fabra, pp. 183-193.

Llanos, García de (1983 [1609]): Diccionario y maneras de hablar que se usan en las minas y sus labores en los ingenios y beneficios de los metales, con un estudio 
de Gunnar Mendoza y comentario de Thierry Saignes, Bolivia, Museo Nacional de Etnografía y Folklore, 1983.

MAFFEI, Eugenio, ed. (1977 [1877]): Centenario de la Escuela de Minas de España, 1777-1877, Madrid, Bicentenario Fundación E.T.S.I. de Minas.

Menéndez Navarro, Alfredo (1995): El Diccionario. Índice de las voces municipales con que se explican es sus faenas los mineros de Almadén (1785) de José Parés y Franqués († 1798), Almadén, Universidad de Castilla-La Mancha, Escuela Politécnica de Almadén.

PARÉS Y FRANQuÉs, José (1785): El diccionario. Índice de las voces municipales con que se explican en sus faenas los mineros de Almadén, manuscrito.

Puche Lorenzo, Miguel Ángel (2002-2003): "La incorporación de tecnicismos mineros a la lexicografía académica decimonónica", Revista de Lexicografía, IX, pp. 131-146.

- (2004): "Difusión de tecnicismos en la lengua de la minería del siglo XIX: la aportación de Sebastián de Alvarado y de la Peña", Revista de Investigación Lingüistica, VII, 199-216.

_- (en prensa): "El léxico técnico de la minería: entre la definición y el préstamo", en Actas del VI Congreso de Lingüistica General.

Real Academia Española (2000): Nuevo Tesoro Lexicográfico de la Lengua Española, Madrid, Espasa, edición en DVD.

Terreros y PANDo, Esteban (1787): Diccionario castellano con las voces de las ciencias y artes y sus correspondientes en las tres lenguas francesa, latina e italiana, Madrid, Imprenta de la Viuda de Ibarra, Hijos y Cía. 


\section{COLECCIÓN DE VOCES USADAS EN LA MINERÍA}

\section{$\mathbf{A}$}

Abarcón (v. Javalcón)

Abras $=$ Aberturas o quebrajos de los cerros que demuestran violenta evaporación subterránea con que se abienta y reventaron. Son señales de minas, como lo son también los riscos que algunas veces tienen estas averturas en los labios.

Abrir mina sobre tierra muerta $=$ Es romper en el suelo donde no hay metal, vena, ni señal de haberla ni de haberla habido. Voz americana.

Abuce $=$ La operación de abuzar.

Abuzar $=$ Es poner en corte agudo o punta dicha herramienta o estaca bota [sic].

Acequia $=$ Zanja o canal que se forma para conducir las aguas en las minas.

Acequiado= Adj. que se aplica al sitio donde hay acequias.

Acequiador $=\mathrm{El}$ que hace acequias.

Acequiar $=$ Hazer o construir acequias.

Acerar $=$ Poner y templar acero en las bocas de las barrenas, martillos, cavaderajes, hachas, \&.

A

4 rón ú

Aetador=

Acodalado $=$ Part. Pas. de acodalar.

Acodalar $=$ Es sujetar dos ojas paralelas en posición vertical a fin de que se contengan los empujes laterales que suelen gravitar a un arco por clavar tableros que sujetan arena, tierra.

Acongrielado $=[\ldots]$ de diferentes piezas que por su avenido y uso de congrieles vienen a formar un todo untuoso y firme.

Acongrielar $=$ Hacer unir aferradamente aunque estén algo desmentidas las puntas de tablas, peinazos, cavidos, cruceros, manquetas, etc., de puertas y ventanas y otras piezas de carpintería.

Acoplado= Par. Pas. de acoplar.

Acoplar $=$ Es avenir o encajar en la luz de un cuadro, cerco, o marco, otro con todos sus gruesos.

Acople $=$ La acción o trabajo de acoplar.

Acostarse el metal= Es variar de una inclinación a otra mayor o que casi se tiende o forma capas.

Acreedores a las minas $=$ En América los escriturarios o instrumentales son preferidos a los demás, y los de una misma data tienen un mismo lugar y prorata o cuota de sus créditos; y sobre todos tiene preferencia el Aviador. Suelen muchas veces convenirse con los mineros deudores de ceder las minas y haciendas por los alimentos que les señalan. 
Ademación $=$ Oficio de ademar.

Ademar $=$ Es forrar y cubrir los postes pilares o llaves aunque sean de metal riquísimo, con maderaje para conservarlos y evitar que los mineros los destruyan para hurtar el metal, o no se pongan ellos mismos en peligro de perder la vida. Voz americ.

Ademador $=$ El operario que adema. Voz amer.

Ademes $=$ Cubiertas o forros de madera con que se aseguran y resguardan los tiros, pilares y labores. Voz amer.

Achicar $=$ Frase que usa la minería para esplicar la diminución o rebaja de las aguas en alguna labor o cañón. Voz amer.

Achicador $=$ Operarios destinados a la labor de achicar. Voz amer.

Achinchinques $=$ Operarios destinados a recojer las aguas de los veneros subterráneos de las minas en unas cuvetas de cuero de toro y conducirlas a las piletas o cajas del tiro. Voz amer.

Adobe $=$ Ladrillo sin cocer que se gasta después de estar muy seco en obras de poca consistencia.

Afinación $=$ La operación de afinar.

Afinador $=\mathrm{El}$ que afina o hace la afinación.

Afinar $=$ Es quitar a las planchas ó tejos de oro, plata, cobre, estaño, \&, las heces que todavía les quedan después de fundidas.

\section{Afino= (v. afinación $)$}

Agrimensor de mina $=$ El que tiene por oficio además de la medición y partición de las tierras, señalar a cada propietario de mina tanto en la superficie, como en los trabajos subterráneos la parte que a cada uno corresponde.

Aguas $=$ El daño que, en América, causan las de minas altas en las bajas se tasa y se paga porque todas las minas deben siempre andar limpias y desaguadas, así por mandarlo las ordenanzas como por la calidad y situación de las minas. Recibir las aguas el predio superior del inferior se estima ser servidumbre, pero solo lo es para dar paso a los desagües.

Aguas $=$ Son la mayor borrasca de las minas y se encuentran en los más altos montes.

*(V. antes aguijón y aguilón)

Aguja magnética $=$ Se llama así en general cualquier hierro que tiene comunicada la virtud de la piedra imán, pero en particular se entiende la flecha de la brújula.

Aguijón= Punta delgada y aguda de hierro que colocan en un palo largo los carreteros que con bueyes conducen el mineral al cerco de fundición, para que éstos anden más vivos.

Aguilón= Madero que en las armaduras con faldón está puesto en diagonal desde el ángulo del edificio hasta el cuadrado.

Aguja de flor= Llámase así la aguja que se emplea al cargar los barrenos de este nombre que por lo regular son de más longitud que una vara castellana. 
Aguja de barreno= Es un instrumento o varita delgada de cobre que se entra al cargar el barreno para colocar la mecha en el agujero que deja en la carga. Deben ser de cobre porque las de hierro al sacarlas suelen dar chispas y prender fuego la pólvora.

Agujas de tapiales $=$ Son unos hierros como del largo de media vara, con cabeza en forma de cruz, para asegurar los tablones que a uno y otro lado se colocan en las paredes cuando sobre éstas se trata de hacer tapias de tierra o barro.

Agujón= Hace en los barrenos dobles el mismo oficio que la aguja en los simples y es siempre más largo y grueso que ésta.

Ahí es= Es un breve equivalente de la suspensión de toda cosa en acción.

Ahí es arriba $=$ Es preposición que usan los mineros, que van subiendo las escaleras, cuando sienten que, por la parte superior, bajan otros que se deben parar en los descansillos hasta que suban los de la parte inferior.

Ahí es abajo= Voz que dicen los mineros que vajan a la mina cuando oyen que otros suben para que éstos se detengan hasta tanto que pasen los primeros de aquel sitio.

Ahondar una mina $=$ Es escavar o profundizarla hasta el término que fijan las ordenanzas, para desde entonces poderla poseer, vender y comprar libremente.

Ahonde $=$ El fondo que los mineros de América deben dar a las minas en el término de tres meses, sin lo cual no se les debe dar la posesión de ellas; éste es cuando menos de 5 varas de ancho, 6 de largo y 7 de profundo. En el Perú deben adelantar este trabajo en 60 días so pena de perderlas.

Ahonde $=$ Cierta estensión que debe darse a las minas que se denuncian por despueble o abondono [sic] en la parte de cata o ensayo que el denunciador quisiere.

Alabastriles $=$ Es una piedra de yeso bastante pura, de media trasparencia, de color de mármol, que se parece bastante al verdadero alabastro, pero que sin embargo es un verdadero yeso. Hállase con especialidad en Alemania y también hay descubierta una bellísima cantera en las inmediaciones de París. El Sr. Poll ha hecho sobre esta piedra muchas esperiencias para poder determinar la verdadera naturaleza de la piedra de yeso.

Alabastro= Es una piedra calcinable algo menos dura que el mármol, su color es vario pero cuanto es más blanca es más trasparente. Le hay que se parece al ónice y también que imita a otras piedras figuradas y que se llama ervasizado; otro tiene el grano del mármol y es de un blanco de leche y muy tierno que sirve a los escultores para sus obras; además le hay de otras diferentes clases.

Alabastrina $=$ Hoja o lámina delgada de alabastro que se usa primeramente en las claraboyas de los templos por su trasparencia en vez de vidrio.

Alabearse $=$ Corvarse o torcerse las maderas de las puertas o ventanas, $\&$.

Alabeo $=$ Se dice de una superficie y [principalmente] de una tabla o madera cuando ha tomado algun vicio conbándose o torciendose, de modo que nunca forma un plano.

Alacrán= Pieza del freno de los caballos o mulas a manera de una sortijuela o clavo retorcido en caracol y sirve para que el bocado prenda en la cabezada. 
Alamandina $=$ Piedra de que hace mención Plinio con el nombre de trocemies, y tiene un medio entre el granate y el rubí. Es de color subido, de un rojo negruzco y más varato que estas dos piedras; le hay matizada de varios colores y con pintas blancas.

Alambre $=$ Hilo delgado de hierro y aún de cobre que le hay de diferentes gruesos. Sirve para cribas y otros diversos usos que tiene en la sociedad.

Albañil= El que trabaja por sus manos en una fábrica ejecutando los dibujos del Arquitecto.

Albayalde $=$ Es una materia blanda, suave, reluciente, pesada y de color blanco aplomado que, por calcinación, se saca del plomo y sirve a muchos usos; pero el principal es el de la pintura.

Alcayata $=$ Clavo de hierro de cuya cabeza sale una especie de codillo que sirve para tender lo que se cuelga en él y también para asegurar las escaleras, ya sea en las piedras o en algunas planchas de los descansillos que hay en las minas entre una y otra escalera.

Alcohol $=$ Piedras relucientes de plomo mineral que, molido y hecho masa, sirve a los alfareros para vidriar las hollas y demás cosas de barro que construyen.

Alcotana $=$ Herramienta con mango de madera como el de un martillo aunque más largo. Tiene un ojo en que entra el hastil y dos hojas a los lados de él cuyos estremos acaban el uno en forma de muela y el otro de hacha. Las hay también con boca de piqueta en vez de la de cortes que sirven para romper y cortar.

Alcribiz $=$ Un instrumento como embudo por cuyo agujero entra o se encaja el cañón de los fuelles en el horno de fundición para soplar y dar aire. Voz amer.

(Solo que esta voz en su debido sitio) Almartaga= Óxido de plomo en forma de láminas o escamas muy pequeñas, semividriosas, de color blanco rojizo y algo lustrosas. Comúnmente se conoce con el nombre de litargirio de plata u oro según se asemeja más o menos al color de estos metales.

Alenmán $=$ Nombre que dan los mineros alemanes a un conjunto confuso de cristales y fragmentos de cuarzo aglutinados y ligados por un gluten o suceo lapidífico, todo revestido con una materia de ocre que muchas veces es de la calidad del cobre. Esta especie de complejo se encuentra en minas de mucho tiempo abandonadas.

Alero= La parte del tejado que sale fuera de la pared para desviar de ella las aguas llovedizas.

Aletas $=$ Sin definición

Alfarería= Fábrica de hacer hollas, pucheros, cántaros, \&, y demás cosas de barro para los diferentes usos de la sociedad.

Alfarero= El que fabrica o tiene por oficio el hacer cántaros, hollas y demás utenselios de barro.

Alicates $=$ Especie de tenazas con puntas muy pequeñas y de diferentes figuras que usan varios artífices en obras menudas y delicadas, de todos metales, ya para retorcer los hilos, ya para asegurar las piececillas que quieren limar, ya para colocarlas en sus lugares y otros usos.

Alidada $=$ La regla movible de que se usa en algunos instrumentos geométricos, como en la plancheta, grafómetro, teodolito \& y también astronómicos para medir ángulos. 
Almacén $=$ Es todo edificio público o particular que sirve para guardar por junto cualesquiera géneros como armas, azogue, comestibles, pertrechos, \&.

Almádana $=$ Instrumento a manera de cazo cuya cabeza es de hierro, igualmente grueso, y chata por ambas estremidades, que está enastado en un mango de madera bastante largo y sirve para romper piedras.

Almadaneta= Es a modo de yunque de hierro de 8 á $9 @$ @. Sirve de cabeza al mozo con que se quiebra y muele el metal para beneficiarlo.

Almadén= En árabe significa la mina. Voz compuesta de el artículo Al y el sustantivo maden. Llámase así el pueblo donde existen las famosimas [sic] minas de azogue en España. También hay otro que se llama Almadén de la Plata que se halla situado en las inmediaciones de Sevilla.

Almádena $=(\mathrm{v}$ Almádana $)$.

Almadenejos $=$ Pueblo situado a al E. de Almaden o 2 de leguas de distancia y en donde se hallan también minas de azogue.

Almijara= El lugar donde el Almijarero tiene el aceite que ha de repartir a los mineros.

Almijarero $=$ Es un hombre que en Almadén tiene el oficio de repartir a los trabajadores mineros el aceite con que éstos se han de alumbrar en lo interior de la mina.

Almohadilla $=$ Se llama lo que se les pone en la cruz del lomo a las mulas y caballos que tiran de las máquinas como para que no se lastimen.

Almohadilla $=$ Piedra de sillería, por lo regular cuadrilonga, que resalta de la obra o mampostería tanto de mina como de edificio.

Almohadillado= Obra de albañilería que tiene la figura de almohadilla.

Almohadillar $=$ Colocar las almodillas [sic] ya sea a las mulas o caballos sobre la cruz del lomo o ya en las obras de albañilería las piedras $1^{\text {as }}$ que tienen la figura de almohadilla.

Almohaza $=$ Instrumento de hierro con que se estrega a las caballerías para sacarles la caspa que crían y el polvo que recojen entre el pelo. Compónese de una chapa de hierro con 4 o 5 serrezuelas de dientes menudos y romos.

Almohazador $=$ El que almoha o tiene el ejercicio de almohazar.

Almohazar $=$ Estregar el pelo a las caballerías con la almohaza para limpiarlas el polvo y barro.

Alma de un arco: La perpendicular tirada desde la clave a la cuerda o su prolongación.

Aludel $=$ Aparato de barro cocido arcilloso de 18 pulgadas de largo, 8 de diámetro de la boca mayor, 9 de la boca menor y 11 del óvalo que sirve en Almadén para que en las fundiciones del azogue en los hornos de Bustamente pase y se condense en ellos el azogue que va en vapor desde el horno.

Almmbraren la mina= Es despedirluzenlos andiles heches a fin.

Alumbre $=$ Es una sal fósil y mineral que resulta de la combinación del ácido sulfúrico con la alúmina y se encuentra sobre la tierra. Su sabor es al principio dulce, pero después tiene una astric- 
ción muy fuerte; lo hay de dos clases, natural que es poco conocido y facticio que puede llamarse así por la [sic] diferentes maniobras que hay que efectuar para sacarle de las minas.

Alumbre de pluma $=$ Es el que naturalmente se halla cristalizado en hilos o filamentos parecidos a los pelos de una pluma.

Alumbre de roca $=$ Es el que naturalmente se encuentra cristalizado en figuras parecidas a las de las rocas.

Alumina $=$ Tierra muy suave y untuosa al tacto más o menos blanca según su pureza que se pega a la lengua y despide un olor térreo particularmente cuando se moja.

Alzaprima $=$ Barra de hierro o madera que sirve para levantar cosas de mucho peso, poniendo debajo de ellas una punta y cargando sobre la otra para que balancee.

Alzaprimar $=$ Levantar alguna cosa con la azaprima [sic].

Alzado $=$ El diseño o dibujo en que se manifiesta o estampa la obra o edificio en su elevación.

Ałzar $=$ Sin definición.

Amainador $=\mathrm{El}$ operario que amaina.

Amainar $=$ Es agarrar y desengachar los cubos quintales, \&, que se suben con el hierro y el cintero desde abajo cargados de metal, solera o zafra para que los zafreros los lleven a vender al parage destinado para ello.

Amaine $=$ La operación de amainar.

Amalgama $=(v$. amalgamación $)$

Amalgamación= La mezcla o masa que forma el azogue con cualquier otro metal puro [...] con el oro, plata y estaño.

Amalgamar $=$ Es mezclar el oro, plata, \&, con el azogue formando de este modo una más blanda.

Ámbar céntrico= $(\mathrm{V}$. succino $)$.

Amenazar ruina un hastial $=$ Frase que se usa cuando está en peligro de caerse el todo o parte de él.

Amatiste $=$ Piedra preciosa de color violeta muy reluciente aunque más claras unas que otras. Admite diversidad de matices: los hay que llaman orientales y occidentales siendo siempre los $1^{\text {os }}$ los más estimados aunque poco comunes. Se halla esta piedra en Bohemia y Silesia.

Amianto= Mineral de color regularmente blanco, sucio, ligero, quebradizo y compuesto de hilos delgados suaves y flexibles; resiste a la acción del fuego.

Amocrisis $=$ Nombre que se da a una arena brillante color de oro, que los Alemanes llaman glimmer amarillo y otros mica.

Amonedar $=$ Sellar o fabricar monedas grabando en ellas el busto y armas de los reyes o los atributos de alguna república. 
Andamio= Especie de tablado arrimado a una pared o hastial, hecho de maderos verticales llamados almas, y otros horizontales llamados puentes, asegurados en los $1^{\text {os }} \mathrm{y}$ metidos en los mechinales.

Anguijuela $=$ Instrumento de carpintería necesario para la construcción de [...] cilíndricos. Son de magnitudes diferentes pero las más pequeñas tienen de largo de 9 á 12 pulgadas, de ancho de 5 a 6 y de grueso 3; sus cajas siendo de madera y figura paralipípeda con un hierro colocado en figura diagonal, tienen un canto cóncavo circular como igualmente sobre [...] dicho hierro.

Angulario= Es una especie de regla de metal con dos puntas en sus estremos para tomar la visual por ellas, y una cuerda de vihuela que pasa por debajo paralela con dichas pínulas, de la que se cuelga la brújula y el semicírculo alternativamente en las operaciones geodesias. Este instrumento tiene una choquezuela para girar hacia todos lados y se coloca sobre un tripie de madera.

Antimonio: Fósil que muy rara vez se halla sino combinado con otras sustancias. El mas común es muy pesado, medianamente duro y de color gris o menos claro.

Andén= Llámase en Almadén al paso circular de las mulas o caballos en la máquina o malacate.

Antropolites $=$ Huesos humanos fósiles petrificados, vitriolizados ó mineralizados; ellos son muy raros y no pocas veces se confunden y equivocan con huesos de brutos o pedazos de ellos que se descubren en las tierras o subterráneos.

Antropomorfite $=$ Crustación petrificada o fósil que se halla en Inglaterra que representa por una parte el rostro de hombre. Su superficie superior está arqueada y como dividida en 3 partes de las que la de en medio es más alta que las otras; es como sus colaterales compuesta de sortijas.

Apagar la cal $=$ Ponerla en remojo o desacerla en agua hasta quedar hecha como una cuajada.

Aparejo= Máquina para levantar las ademas de los tiros cuando se hunden o desquicien, y también para levantar las vigas gruesas que llaman claves y en que estrivan los malacates.

Aperador $=$ El que tiene bajo su mano todo lo preciso para el seguimiento de los tiros, norias, \&, y los distribuye según conviene. Voz amer.

Aperaltado $=$ Arco ejecutado con más punto que la mitad de su luz sin que llegue a ser apuntado.

Aperaltar $=$ Dar a un arco de medio punto más elevación que el radio.

Aperos $=$ Todas las cosas necesarias para el creciente de los tiros, escorias, composición de máquinas, galeras y demás conducentes a las obras subterráneas de las minas. Voz amer.

Apique (trabajar a)= Cuando se profundiza verticalmente en las vetas clavadas. Voz amer.

Apisonar $=$ Apretar o macizar dando golpes con el pisón.

Apuradoras ó dores $=$ Las o los que tienen el oficio de apurar. Voz amer.

Apurar= Buscar las partículas de metal que quedan en los derrames de las haciendas de azoguería. Voz amer.

Arapera $=$ Tabla que vuela y no hace ras con el madero peinazo en que es clavada 
Árbol= Pie derecho desde el que se ramifican todas las partes que componen una máquina o malacate de caballos.

Arca de agua en las minas (V. recipiente).

Arcilla $=$ Se da este nombre a la alúmina cuando se halla mezclada con otras tierras y con óxidos o cales de hierro, que la dan el color amarillo, rojo y otros con que se la encuentra. La usan los alfareros para fabricar loza ordinaria, tejas, ladrillos, hoyas, tinajas, cántaros, \&.

Arco= Fábrica de figura curva dura con cavidad suele estar en su parte inferior

Arco abocinado $=$ El que por un lado es mayor que por el otro.

Arco de medio punto= El que tiene la figura de un semicírculo.

Arco apuntado= El que se compone de dos partes: de arco y círculo u otra cualquiera curva formando ángulo curvilíneo en su clave.

Arco de bofetón $=$ Sin definición .

Arco de cadeneta $=$ El que tiene la figura de la curva cadeneta, catenaira o funicular; esto es la forma de la curva o pandeo que describe un [sic] cuerda o cadena fija de sus estremos.

Arco de vuelta de cordel (v. Arco de cadeneta).

Arco capialzado o remontado= Aquel cuya altura es mayor que la mitad de su luz o cuerda.

Arco carpanel $=$ El que se compone de 9,5,7 partes de arcos de círculo trazados desde centros diferentes. Tiene muchísima semejanza con el arco de vuelta de cordel.

Arco adintelado $=$ El que está en dirección horizontal y se compone de varios sillares labrados en forma de cuña.

Arco de encuentro $=$ El que es común a dos bóvedas que se encuentran penetrándose una a otra.

Arco a regla (v. Arco adintelado)

Arco de apoyo= El que se construye solo con el objeto de que estrive en el cualquiera otra de mampostería.

Arena $=$ En general es un cuerpo seco, duro, impenetrable al agua sin que entre las partículas que la componen haya adherencia alguna; las hay de varias clases y tamaños, como desde el grueso de una haba hasta hechas casi polvo.

Arena arcillosa $=$ Es la que se compone de fragmentos de mica, talco, \&, o en pequeñas hojuelas de varios colores.

Arena calcárea $=$ La trituración hecha de conchas marinas y otros semejantes cuerpos del mar. Hállase en ella corpúsculos minutísimos como de perlas, redondeados por la acción de las aguas.

Arena estéril $=$ La que absolutamente tiene nada de materias metálicas.

Arena metalífera= Dícese de aquel conjunto de partes metálicas de distinto género que se encuentran en muchos puertos o playas del mar. 
Arena volátil $=$ Es un cuerpo tan singularmente tenue que el aire la levanta y lleva en gran cantidad y a mucha distancia, formando bancos y dunas y, muchas veces, abismos tan profundos que cubre y sepulta para siempre en sí a los caminantes que pasan por ella en tiempo de uracanes o vientos impetuosos.

Argamasa $=$ Mezcla hecha por lo común de arena y cal para fabricar.

Argolla $=$ Especie de anillo grande y fuerte de hierro. Émplease entre otros usos para atar las mulas o caballos del ranzal.

Armadura $=$ El maderaje que cubre un edificio y recibe la teja, pizarra, plomo, \&, que forma la cubierta esterior.

Armadura de vomba $=E l$ conjunto de las piezas [principales] que la componen.

Armar la máquina o vomba $=$ Colocar todas sus piezas de modo que pueda ponerse en uso.

Armas de la brújula= Los círculos de metal que sirven para suspenderla de las cuerdas.

Armas de la garrucha= Los hierros que están fijas [sic] y de las cuales sale para la parte superior un gancho para colgarlas donde convenga.

Armella $=$ Anillo de hierro u otro metal que suele por lo común tener una espiga para clavarle en parte sólida como son aquellas por donde entra el mástil del candado o cerrojo.

Armilla $=$ Es una ensambladura inversa de la espiga que entra en escopladura de un madero $u$ otra pieza de hierro, pues a ésta le quedan las $2 / 3$ partes de madera que para la espiga se quita saliendo, saliendo solo la otra $3^{a}$ parte que es el lugar de dicha espiga. Úsanse éstas en unir la testa de un madero con el costado de otro que tendrá su espera de contra armilla.

Armillado= La unión efectiva de piezas por medio de la armilla.

Amoniaco $=$ Piedra que según su denominación debe haber venido de la provincia de Armenia, que se halla con abundancia en las minas de Alemania y con especialidad en las de plata. Su color de un verde azulejo y se saca de ella un azul de monte para los pintores, pero más subido o más claro uno que otro; pero esto no proviene tanto de la naturaleza de la piedra como del modo de purificarla, lavarla y molerla limpiamente.

Arnero de alambre $=$ Cajón a manera de criva que sirve para cerner el mineral que quebrantado ya, o reducido a menudos chipatitos, se trata de cerner para beneficiarlo bien por agua o por amalgamación.

Arnero de cuero= Especie de criba de cuero con agujeros que sirve para quitar el polvo a la paja y cebada que han de comer los bueyes, mulas, $\&$.

Arqueta $=$ Sin definición.

Arrastrar los tiros= Llevarlos por el suelo o sobre el lado yacente de un torno tirando de ellos.

Arrastre $=$ Llámase asi la acción de arrastrar los tiros.

Arrear las mula [sic] o caballos $=$ Ponerlas los pertrechos que necesitan para tirar de las máquinas o llevar alguna carga. 
Arriera $=$ Sin definición.

Arrimadas $=$ Llámase así en Almadén cada porción de mineral que se aproxima a la boca de los hornos capaz de cargar uno de éstos; y se dice 4 arrimadas, 10 arrimadas, $\&$.

Arrimado de mineral $=$ El trabajo que se hace de llevarlo desde los depósitos al boca [sic] de los hornos de fundición.

Arrimadores de mineral $=$ Los que se ocupan de llevar el mineral a las proximidades de los hornos de fundición para después cargarlos.

Arrimar el mineral= Es llevar a la boca de los hornos lo que se necesita según van fundiendo las hornadas.

Arsénico= Materia mineral formada en diversos pedazos duros, pesados que se quiebran fácilmente, muy blancos, lisos, resplandecientes y de una sustancia sulfúrea y caústica.

Arte de viento $=$ Sin definición .

Artesa $=$ Sin definición .

Artesón $=$ Sin definición.

Asarmelado $=$ Par. Pas. de asarmelar

Asarmelar $=$ Es construir el alarife la parte de mampostería que ha de recibir las primeras dobelas de arco ó bóveda.

Asas $=$ Argollas de hierro de figura triangular que sirven para llevar de ellas los cubos, tinas, morteros, \&, con la diferencia de ser unas de éstas mayores y más fuertes que otras según la resistencia que tienen que hacer.

Asentista de escavación $=$ El que por un precio ajustado toma en las minas algún sitio por escavar con la condición de pagarle un tanto por cada vara cúbica siendo de su cuenta pagar los destajeros, pólvora, aceite y pajuelas. En Almadén se fija además el jornal que deben pagar a los destajeros por cada barreno de 13 [pulgadas] que suele ser de 10 a 12 reales.

[Asgadura de hierro]= Sin definición.

Asiento= Llámase así en Almadén la operación que hacen de nombrar los sujetos que van a entrar a trabajar ya en las minas o ya en los cercos de la superficie para poder llevar cuenta de los jornales que cada uno devenga.

Asiento $=$ Lo que ha rebajado una mampostería o arco al cabo de algun tiempo que se levantó.

Asón $=$ Es en los cubos un hierro curbo semicircular con un medio gozne en cada estremo, que arma en otras que tienen las orejas que sirven cada una en posición diagonal de dichos cubos. En las cubas-tinas de máquina no tienen curca y para proporcionar atadura para el tiro, un ojo redondo.

Aspar $=$ Se dice de la enmaderación que se hace o con que se revisten los tornos, y es cuando los entivadores no han tomado con perfección las medidas de las distancias que hay de un bantrote a otro y que han dejado más ancho por un lado que por otro.

Aspas $=$ Sin definición. 
$[\mathbf{H}]$ astiales $=$ Son en las minas y sus obras los dos lados, costados o lienzos de las venas y también del torno, y ocupan y terminan la anchura de ellos. Son efectivamente como sus paredes y ellos se denominan pendientes y yacentes conforme su situación; porque el pendiente es aquel que tiene sobre sí la parte del terreno y está en la parte superior de la mina o torno, y el yacente es el que está, por decirlo así, echado o recostado y tiene sobre sí la mina por su parte inferior. Bajando el torno oblicuo es el astial pendiente el que tenemos de espaldas y el yacente el que tenemos por delante. En las venas es el astial pendiente el que cubre y sirve como de techo, y el yacente es el sobre que descansa la vena.

Atacadera = Instrumento de hierro que sirve para atacar el barreno; no debe tener nada de aceros porque no haga chispas antes de tiemo [sic]. En algunas partes suelen ser de madera dura y son más seguros aunque duren poco tiempo.

Atacadera de flor $=$ La que sirve para atacar los barrenos de flor o de más de una vara de largo.

Atacador $=($ V. atacadera $)$.

Atacar el barreno= Es apretar los tacos y pólvora en términos que no queden muchos insterticios [sic] para que salte bien la piedra. Practican esto apretando con la atacadera a fuerza de martillo los boliches o tacos que se van poniendo sobre el cartucho de pólvora ya introducido.

Atadero $=$ Cuerda que sirve para atar.

Atadores de azogue $=$ Los que tienen el oficio de empaquetarlo y atarlo en baldeses cuando hay escasez de frascos de fierro.

Atados de azogue $=$ Lo mismo que paquetes, esto es, cierta porción de azogue que aseguran y meten dentro de bolsas de baldes cuando hay falta de frascos de fierro.

Atajador $=$ Mozo que trae las mulas o caballos al tiempo de mudarlos o relevarse para tirar de las tahonas, molinos y desagües. Voz amer.

Atajar el agua $=$ Es detenerlas en los canalones o azequias.

Atarugado $=$ Lo que se halla clavado con pasadores de madera.

Atarugar $=$ Sustituir con pasadores de madera la clavazón de fierro.

Atizar $=$ Los hornos. Es echar poco a poco y en haz de cada vez de monte bajo para verificar la cochura en los hornos de fundición de azogue en Almadén.

Atizonar $=($ V. atizar $)$.

Atar valdeses al azogue $=$ Liarlos con más cuerdas de modo que no pueda salirse metal alguno.

Atecas $=$ Los sirvientes que echan el agua de los planos de las minas en las botas o tinas para que salgan por los tiros. Voz amer.

Atesterar las soleras $=$ Es llenarlas de mineral, zafra o materiales hasta que no cave mas.

Atesterar $=$ Sin definición.

Atierres $=$ Las tierras que impiden el mode la labor y deben sacarse a los terreros. Voz amer. 
Atinconar $=$ Es asegurar provisionalmente algún hastial con rollizos o puntales para que no se caiga abajo.

Atinoar $=(\mathrm{V}$. verde monte $)$.

Atirantar $=$ Asegurar con tirantes.

Atornillar $=$ Es afirmar algún madero o pieza de hierro con tornillos.

Audiencia $=$ Tribunal que tiene conocimiento del gobierno de las minas, en lo gubernativo civil, criminal y económico. Hay estos tribunales donde las minas se benefician por particulares, en Alemania, Hungría, Mégico y el Perú.

Avenida $=$ Es en las minas el paso de unas labores a otras.

Avenido $=$ Lo que se aviene.

Avenir un contrato $=$ Es ajuntarle o concordar las partes unas con otras.

Aventador= Máquina que sirve para sacudir, mudar y purificar el aire de las minas y habitaciones.

Aventar $=$ Mudar y purificar el aire de una mina o habitación.

Aviador $=$ El sujeto que en las minas apresura y aviva la ejecución de las labores y demás maniobras que se están haciendo.

Ayudante de minas $=$ El que a faltas de los oficiales hace sus veces.

Ayudante de obras= El que hace las veces del Maestro.

Ayudante de fundición= El que auxilia a los oficiales de fundición en sus fundiciones.

Azada $=$ Instrumento para cavar la tierra. Es una plancha de hierro plana y chata con un hastil de madera como de media vara de largo.

Azadón= Instrumento que sirve para cavar la tierra. Se compone de una pala de hierro, algo corva, con dos puntas en uno de sus estremos y en el otro un anillo donde se encaja y asegura un hastil, como de una vara de largo.

Azavache $=$ Es una sustancia vituminosa, dura, negra, seca y unida que se halla en España en las minas que hay en Asturias, de donde se saca para distintos fines. Se ha de escoger limpio y duro, pero quebradizo de un color negro resplandeciente.

Azadon= Sin definición.

Azogue $=$ Es un metal líquido de color de plata, muy pesado, pero fácil de evaporarse con el fuego y penetrable; se une y amalgama con el oro y plata, y también con el estaño y plomo. Se saca de varias minas de Europa, pero el mejor y más abundante de todos es el que se estrae del Almadén, donde se separa de la piedra mediante el fuego en hornos hechos esprofeso.

Azoguera $=$ El parage en que se ejecuta el beneficio del oro y la plata por medio del azogue.

Azoguería = En Nueva España, la oficina donde se incorpora el azogue y otros ingredientes con el mineral molido para estraer la plata. 
Azoguero= En Nueva España, el que tiene por oficio el incorporar el azogue, sal y magistral en los montones de la mina molida de la plata para el beneficio de este metal.

Azolar $=$ Desbastar la madera con la azuela

$($ Azolbado $=\ldots$ azolbarse $)$

Azuela $=$ Instrumento corto que al estremo tiene un hierro ancho muy afilado que sirve para desvastar madera.

Azufre $=$ Fósil de color amarillo mas o menos vivo que se encuentra en masa o cristalizado en diversas formas. Es quebradizo, ligero y algo craso al tacto. Frotado se electriza y despide un olor particular y en el fuego arroja una llama azul y olor sofocante. Sirve en las minas para hacer pajuelas para prender fuego a los barrenos.

Azul de Prusia o de Berlín= Es una materia de color azul que se hace de sangre de buey y sirve a los pintores. La carestía del ultramarino que se hace del lápiz lázuli, y lo poco que se encuentra dio motivo a este hallazgo en 1704 por un habitante de Berlín. No es este azul poco menos bueno que el otro, sobre todo mezclado con él hace el mismo efecto y es mucho más varato.

Azul de Suceberg= Es un compuesto de cobalto y de cuarzo blanco, fundido junto y después unido con potasa, lo que produce un vidrio azul que hecho pedazos se muele y repasa por cedazos o tamices, y se conserva en unos vasos que se sellan con una mara de su calidad y especie.

Azur $=$ Es un color azul que se hace de lápiz lázuli o de piedras del Occidente y que no sería difícil de comparar con el que se puede hacer con el cobalto, porque el azul de este mineral es tan bello como se puede desear.

Azolbado $=$ Se dice de un cañón que no permite la libre estracción del agua por medio de lodo, zafras, astillas, \&.

Azolbarse $=$ Es lo mismo que atascarse. Aplícase a los cañones de las bombas cuando impiden el lodo, zafra, \&, la libre salida de las aguas.

Azolbarse $=$ Voz usada entre los mineros que se aplica cuando el hombre queda sin la acción ni movimiento respecto la visión de alguna ruina o peligro.

Bacisco= Llámanse en Almadén los chinatos menudos y polvo de mineral que resulta después de quitar de un montón las piedras gruesas.

Bataje= Sin definición

Balancín $=$ Sin definición

Batmat $=$ Sin definición

Balaustrada $=$ Varias tramadas de balaustros que sirven de barandilla y se ponen en el brocal de los pozos y tornos.

Balaustre $=$ Columnilla de madera, hierro, piedra, $\&$, adornada con molduras redondas o esquinadas. 
Bálbula $=$ Se da este nombre en Almadén a una piedra redonda que, con un aro alrededor y gancho de hierro en el medio para agarrarla, se coloca en una boca circular que, en la parte superior, tienen los hornos de fundición. Su dimension es de tres cuartos.

Baldeses de Azogue $=($ V. Atados de azogue $)$.

Baldosa $=$ Ladrillo cuadrado cocido que sirve para solar.

Balasa $=$ Es una piedra preciosa algo menor que el rubí en el tamaño y de un color de rosa. Es como la matriz que engendra el rubí. Hállase esta piedra en los montes de Sajonia, pero no tiene la solidez ni dureza que las orientales y es de menor valor que los rubíes.

Bancos $=$ Peñas fuertes que levantan y estrechan las vetas o las hacen tomar otro rumbo.

Bancos de minas $=$ Elevaciones que se forman escavando unas tras otras otras [sic] a manera de gradas, que al parecer son asientos sobre que los mineros pueden sentarse y trabajar unos tras otros sin embarazarse ni impedir sus operaciones. Estos se forman al abrir una caña o galería y también al escavar un pozo o torno.

Banderilla $=$ Sin definición.

Bancos de arena $=$ En las minas, son camadas poderosas que se encuentran en sus obras al profundizar algun torno, y que es indispensable romper para llevar al fondo de ella.

Bantrote $=$ Palabra tomada de la alemán Wandtruhe y es un palo derecho del largo que es el tramo $1^{\circ}$ del torno que se pone en los 4 angares y otros dos en medio del hastial en pendiente y yacente contra el que se aseguran los estemples.

Sin definición.

Baratatan $=$ Sin definición.

Barandón de alambre $=$ Cajon redondo o cuadrado a manera de criva que sirve para pasar por el la cal fina o que se emplea en obras delicadas.

Barlete de carpintero $=$ Sin definición.

Barra= Instrumento de hierro calzado que sirve para palanquear las piedras que se arrancan de la mina o cantera. Las hay de varios tamaños, por lo regular suele ser de $1 \frac{1 / 2}{2}$ vara de largo y $21 / 2$ palmos de grueso en forma cilíndrica.

Barra $=$ La parte que cada dueño tiene en una mina que suelen ser dozavas o veinticuatroavas partes, según como se suponga dividir la mina, [tachado] partes que se llaman barras. Voz amer.

Barras $=$ Las minas en América se componen de 12 barras o de 12 partes en que puede tomarse cualquiera por las acciones que quiere. Las que se llaman dobles se dividen en 24 , pero lo más regular es en 12. Ellas pueden subdividirse y el lucro de ellas entre multitud de compañeros. En consecuencia de lo cual, cada compañero concurre al costo y percibe el fruto según el número de las barras que le pertenecen, como en una herencia; y si algunas veces unos perciben más lucro que otros y han contribuido menos o deben contribuir menos en los daños pérdidas de las minas. Esta desigualdad es en virtud de pactos particulares que son lícitos en muchas negociaciones. 
Barras $=$ Llámanse así los trozos de oro, plata y otros metales que se reducen a tal estado en las fundiciones. En América, después de hechas, deben manifestarse a los oficiales reales para diezmarlas y de ellas sacar lo que toca al Rey, pues sin esto está prohibido el hacer negocio.

Barrear $=$ Trabajar con la barra arrancando piedra.

Barrena= Instrumento de hierro de diferentes gruesos y tamaños con una manija de palo atravesada arriba. En la parte inferior tienen unas roscas hechas en el mismo hierro, el cual sirve para atadura o hacer agujeros en la madera.

Barrena $=$ Hierro redondo del diámetro de una peseta y la boca cortante en forma de un arco muy suabe con cabeza y punta calzadas de acero, larga como de 2 tercios á 3 quartos para barrenar las peñas y darles cohetura. Las hay también con 4 filos en cruz en su boca, pero las $1^{\text {as }}$ está observado en Almadén que son las más económicas y mejores al intento.

Barrena de azotar $=$ La que se emplea en los barrenos de este nombre.

Barrena de flor $=$ La que sirve para abrir los barrenos de flor que suele ser de más de una vara de largo y algo más gruesas que las comunes.

Barrena alemana $=$ No se diferencia de la común sino en que ésta tiene 4 filos en forma de cruz en su boca.

Barrena de teja $=$ Sin definición.

Barrena de una pieza larga $=$ Sin definición.

Barrena de taladrar $=$ Sin definición.

Barrena con asta $=$ Sin definición.

Barrena de dos brazos $=$ Sin definición.

Barrena de gusanillo $=$ Sin definición.

Barrenar $=$ Es hacer barrenos.

Barrenar una mina $=$ Es lo mismo que disfrutar o beneficiar una mina.

Barrenar con veta en mano= Quiere decir labrar minas con existencia segura de metal; cata que se hace legítimamente con demostración que no se trabaja por suposición de fruto que no hay, $\mathrm{y}$ que se quiere abrir torno o socabón con ánimo de usurpar vena de otros o disfrutar el metal que hubiesen descubierto. Cualquiera que pide estacas, esto es, posesión de mina que hubiese descubierto con manifestación de fruto, ha de ser puesto en posesión del terreno que pide, con las medidas del largo y ancho que conceden las ordenanzas de minas en América.

Barrenarse las minas $=$ Hacer la comunicación entre las minas o trabajos de ellas.

Barrenero $=\mathrm{El}$ que tiene por oficio o se ocupa en abrir barrenos.

Barreno= Agujero redondo que se hace en la piedra con barrena y a golpe de martillo. Son de diferentes tamaños conforme el efecto que se quiera hagan, lo más regular es darles de 14 a 18 pulgadas de hondo, después se carga con un cartucho de pólvora de dos onzas que, después de atacado con boliches, se enciende con la mecha y pajuela para hacer saltar la piedra y despedazarla, quebrando de esta manera las peñas más bravías y duras. 
Barreno $=$ La comunicación de las minas unas con otras

Barreno $=$ El agujero que los carpinteros abren en la madera para entrar los tarugos y clavos.

Barreno= El lugar de la peña que ha barrenado.

Barreno simple $=\mathrm{El}$ que se construye por un solo destajero teniendo la barrena con la mano izquierda y el martillo con que sobre ella da golpes en la derecha.

Barreno doble $=E$ El agujero que se abre en la roca por dos destajeros teniendo uno la barrena con ambas manos y dando el otro los golpes con el martillo y a toda fuerza.

Barreno de flor $=$ El que se abre en la minas, de una vara o más de hondo cuando se trabaja en sitio donde se sospecha resulte un golpe de agua. Este barreno se va adelantando a medida que se continúa abriendo la caña o galería.

Barreno atajado= Se llama cuando el destajero que le ha hecho no ha tenido cuidado de dar vueltas a la barrena; y así ha no resultado cilíndrico y se atasca la barrena.

Barreno azotado= Es un barreno simple que se pone cuando se lleva el descalce por el banco dejando escuetos los lienzos y arroja por lo regular más piedra que los demás barrenos.

Barreno de arroje y levante $=$ Es el que se pone cuando no obstante de muchos abiertos ya no salta la piedra a causa de los lisos y rafas de ellas. Éste se abre en la [frente] o llano del banco y se le suele dar 20 palmos de hondura o más si se juzga necesario para descabezar o descogollar el banco.

Barretero $=$ Operario que trabaja en la mina o cantera con barra, cuña y pico. Voz amer.

Barril para agua dulce $=$ Cuba que acostumbran tener los mineros en los tajos para beber agua, y suele ser como de una vara de alta, 1/4 los diámetros de las bases y como 14 pulgadas el del medio.

Barro= Masa que resulta de la mezcla del agua con la tierra.

Basalto $=$ Es un género de piedra mármol estremamente bronca, de color de hierro o de un pardo negruzco. Es muy angulosa y de una especie de prisma de 4, 5, 6 y a veces 7 lados. Por su dureza y tamaño sirven de apoyo en las puertas de las casas, esquinas de las calles y de mojones o linderos en los campos. Ella es una especie de piedra de toque; no se calcina como el mármol, antes bien se vitrifica. Viene de Bisaltri, provincia de la Macedonia, de donde trae su nombre, y Plinio dice que se haya en Ejipto. Lo que si es cierto que se encuentra en Alemania, en Stolpen y en Bohemia; y que una tierra arcillosa y ferruginosa la sirve de basa.

Batidera $=$ Instrumento de hierro con que se mueve y mezcla la arena y cal, que se compone de un palo largo y en un remate una plancha de hierro con el corte hacia abajo.

Batiente $=$ La parte del cerco de las puertas, ventanas y otras cosas semejantes en que se detienen y baten cuando se cierran.

Batir suela $=$ Es machacarla con el martillo a fin de que tome más consistencia, bien para emplearla en las bombas o vasijas, $\&$. 
Batir cal $=$ Revolverla y menearla con la batidera o raedera para mezclarla con el agua.

Belemnitas $=$ Estas piedras que también se llaman artroitas o estrelladas por su figura en que representan a las estrellas uniéndose muchas de ellas y acabándose en forma de dedos en punta; aunque las hay que por arriba y por abajo, son de una misma forma. Es cierto que para no hallarse en minas y por no tener cosa que pertenece a lo que se puede llamar mineral, parece que no pertenece a este reino; sin embargo, como se encuentran en fondo de arena, es sensible que igualmente que el oro y por el mismo motivo se debe incluir en la misma clase.

Belorta $=$ Anillo o rosca de hierro que asegura la empalmadura de los palos que se colocan en los brocales de los tornos y pozos de las minas.

Beneficio de los metales $=$ Labor y cultivo que se da a las minas para disfrutar estos.

Bermellón= Fósil que se compone de azogue y azufre. Es sumamente pesado, de un hermoso color rojo y de grande uso en las artes. En Almadén se fabrica desde que el famoso D. Diego de Larrañaga descubrió su elaboración después de un viaje a Alemania por el Gobierno.

Bibliquí= Sin definición.

Bilorta $=(V$. Belorta $)$.

Bam $=$ Sin definición.

Bismuth= Género de plomo de color ceniciento; sustancia mineral que tiene diferentes nombres y se encuentra debajo del estaño a quien al parecer sirve de matriz o basa. Unas veces se halla en venas y otras tiene también partículas de cobre y hierro y no carece de azufre y de arsénico. Obedece mucho al fuego y deja una tierra de residuo que es parda y los alemanes llanan [sic] rei. Esta tierra es la que nos da aquel azul tan precios [sic] que viene de dicho país.

\section{Bitumen judaico $(* *)$}

Blenda $=$ Es una especie de mineral de color negruzco y también tira á amarillo, muy reluciente como la pez rubia, y sumamente hermoso a la vista.

Bitumen judaico= Es una materia sólida, fácil de quebrarse, y parecida en el color a la pez negra; echada en el fuego se inflama y despide un holor fuerte y desagradable.

Boca $=$ Es la abertura $1^{\text {a }}$ que se hace sobre la veta.

Boca de la barrena= Es el corte o filo acerado con que hace saltar la piedra en polvo cuando se está abriendo el barreno.

Bocas del martillo= Aquellas dos partes de éste con que el destajero o barrenero da los golpes en la cabeza de la barrena.

Bocamejora $=$ Tiro para comunicarse con la estaca fija y facilitar la labor interior de las minas. Voz amer.

Bocatijera $=$ Sin definición.

Bocazo= Se llama cuando en un barreno ya atacado y al cual se ha prendido fuego sale la pólvora sin quebrantar piedra, a la manera que cuando se dispara un tiro con una escopeta; y entonces se dice "ha dado bocazo". 
Bochorno $=$ Escesivo calor que por falta de ventilación apaga las luces dentro de las minas, omisión en haber hecho cruceros para que devane el aire. Con los efluvios que despiden los operarios con la fatiga que los aumenta se apagan, pues, las luces. Es menester en tales lances que algunos de ellos salgan con lo que suele volver a tomar aliento la llama. Voz amer.

Bofetón= Se dice que se da de bofetón cuando los trabajadores que, entre los lisos de las piedras, tienen clavada la cuña, en vez de sacudirla en su cabeza verticalmente, la dan junto a ella con la porra de hierro horizontalmente.

Bohedal $=($ V. criadero $)$.

Bolandera $=$ Sin definición.

Bol arménico u oriental $=$ Es una tierra que se trajo de la Armenia y es abundante en las minas de hierro, y se halla en todas partes donde hay tierras ferruginosas.

Bolante= Sin definición.

Bolas de piedra $=$ Son unos cuerpos redondos y regulares que entre las escavaciones se encuentran sin enlace alguno con otros de su misma calidad, ni tampoco se hallan en dirección de filones.

Bolas de bacisco= Nombre impropio que se da en Almadén a unas pirámides cuadradas, truncadas de [ ] pulgadas altura y el lado del cuadrado de la base mayor de [...] pulgadas y el de la menor de unas [...] pulgadas. Se forman con las cabezas o bacisco mezclado con agua y, despues de secas, se echan en la parte superior del cargo en los hornos para fundirlas juntamente con lo demás del mineral.

Boliches $=$ Cilindritos que se hacen con barro encarnado como de unas 4 pulgadas de largo y $1 / 2$ de grueso que sirven o se emplean en atacar los barrenos, y también el lodarlos cuando destilan agua.

Bolichera $=$ Sin definición.

Bolillo= El palito redondo que se usa en Almadén para hacer las vainas de papel de los cartuchos de pólvora.

Bomba= Máquina para sacar las aguas de los pozos y calderas de las minas.

Bombero $=\mathrm{El}$ que se ocupa en tirar de las bombas.

Bombo $=$ Se llama la $1^{\text {a }}$ bomba que recibe inmediatamente el agua de la caldera y se la comunica después a las de la parte superior.

Bonanza $=$ Se dice cuando se encuentra labor de metales ricos. Voz amer.

Boqueta $=$ Se llama en la minería cualquier respiradero que se procura dar a las minas sea por cima de la misma superficie de la tierra en linea vertical, o bien sea en línea oblicua porque siempre pueden ser penetrados por el aire para que ventile por las cañas y las refresque, como también a los trabajadores que en ellas se ocupan.

Boquete $=$ Es una avertura cuadrada menor que el brocal y sirve para la entrada y salida del agente en el torno por medio de escaleras de mano que sirven para el descenso; tiene su puertezuela y su candado para cerrarla. 
Botator $=$ Sin definición.

\section{Botar (V.zaca).}

Borrascarse la mina (V. emborrascarse).

Botador $=$ Instrumento de hierro a manera de cincel para arrancar los clavos que no se pueden sacar con las tenazas.

Botas $=$ Son unas vasijas que se usan en algunas minas de un cuero entero de buey para sacar las aguas por los tiros. (V. zaca).

Bóveda $=$ Se llama en las minas a todo techo arqueado o artesonado que forma concavidad o no es superficie plana.

Brazos $=$ Son unos hierros agarrados a los codillos y a las varas de las máquinas y bombas. Ellos están sugetos por una parte a los codillos y, si las bombas que mueve la máquina son dos, entonces tienen estos brazos movimiento alternativo de subir y de bajar conforme bajan o suben las baras que mueven los pistones o sifones dentro de los cañones de las bombas.

Brocal= Llámase en las minas a la parte superior de los pozos y tornos de ellas. Éstos por lo común son rectangulares, aunque también los hay elípticos y de otras varias formas.

Brontia (V. Bufonites)

Buena construcción $=$ Voz general que se aplica a toda obra que bien concluida está conforme al objeto a que se dedica.

Bufonites $=$ Sin definición .

Buitrón= Es un sitio largo, solado, parejo donde se ponen los cuerpos o cajones para beneficiar el mineral.

Buitrones $=$ En Almadén, del azogue se llama al cerco que, dentro de sí, contiene los 9 pares de hornos de fundición, sentaduría, almacén de azogue, \&.

Buje $=$ La rodaja de hierro con que se calza interiormente la boca de los cubos de las ruedas de las carretas para que no luda contra el eje.

Buril de tornear $=$ Instrumento de acero que tiene la punta en figura de escoplo.

Bufones $=$ Son los que en las minas abandonadas buscan el metal para disfrutarle o dar noticia donde le hay para que les premien por el hallazgo. Voz amer.

Buzar el filón= Es cuando éste se inclina a una u otra parte; y así se dice buza a P. L. \& cuando su inclinación es a P. L. \&

C

Caballete $=$ Instrumento de madera que se compone de 3 filones de madera que van a reunirse en un punto y que en sus pies tienen unas puntas de hierro para afirmarlos mejor en el piso. Sirven para tirar cuerdas en la superficie clavando la muletillas [sic] en la parte superior del instrumento y también para lo interior cuando la roca es dura y no pueden clavarse estas con facilidad. 
Caballo $=$ Dureza de piedra firme que se nota al labrar tiro o caña.

Cabeceadero $=$ Sin definición

Cabecear $=$ Es menearse cualquier madero, no estar firme ni seguro y necesitar reparos.

Cabestrillo de sierra $=$ Sin definición.

Cabeza de la vena o filón= Es el estremo mas inmediato a la superficie y que varias veces se ve sin escavar.

Cabeza de la barrena $=\mathrm{El}$ estremo opuesto a la boca y el cual recibe los golpes con el martillo al abrir el barreno.

Cabeza de cuadrilla $=$ Se llaman en Almadén a ciertos entivadores que tienen a su cargo varios operarios y que disfrutan algún haber más que éstos.

Cabezas $=$ Se da este nombre en Almadén a el polvo y menudos chinatos que se recogen en los depósitos donde ha estado el mineral y con las cuales se hacen amasadas con agua, las que se llaman bolas de bacisco.

Cabria $=$ Sin definición.

Cabriales $=$ Sin definición.

Cadena $=$ Instrumento hecho de alambre que se usa en la Geometría para medir las cuerdas. Se compone de cierto número de eslabones cada uno de longitud determinada, como de 1 pie, $1 / 2: \&$, de cada diez de éstos cuelga una laminita en la cual esta numerada la cantidad de pies, varas..., que hasta allí se encuentran. Las estremidades tienen 2 anillos fuertes de más de una pulgada de diámetro para que por ellos entre el jalón, barrena, \&, para estirarla y para que así se pueda estender con más fortaleza.

Cadera $=$ Sin definición.

Cadmia $=$ Se ha dado este nombre a varias sustancias como de hornos ferruginosa, fóssil, \&, la que se llama de hornos es una tierra, polvo o harina sublimado por el fuego que se queda pegado en las partes interiores más elevadas de los hornos donde se funde el cobre, el lugar que la que proviene de la calamina es un verdadero régulo de zinc porque sirve para hacer latón del cobre.

Caducar la mina $=$ Es estar en peligro de undirse.

\section{Cajas o cola de milano (V. fin)}

Cajón= Se llama el metal que se trata de beneficiar cuando después de quemado o incorporado con azogue, agua y sal se comienza a repasar en el buitrón, y su peso son cincuenta quintales de harina o metal.

$\mathbf{C a l}=$ Es una materia blanca que proviene de una cierta piedra de especie calcárea quemada en un horno que se hace a propósito para ello, reducida a ceniza la apagan a fuerza de agua y entonces sirve en las obras de mampostería, esto es, a los albañiles. La bondad de la cal se conoce en el pesol [sic] de la piedra que, según su tamaño, debe ser ligera, luminosa y de sonido hueco y que, cuando se la apague, eche muy fuerte humo. La cal que sale del horno como arenisca es de muy poco precio. 
Calafate $=$ Sin definición.

Calahuezo $=$ Sin definición.

Calamina $=$ Es un mineral que encierra el zinc, o una piedra metálica de color amarillo blanquecino y una sustancia que se halla con abundancia en la Bohemia. En los hornos y fundiciones donde se trabaja mucho zinc y plomo se pega en lo más inferior del interior de las paredes una sustancia no muy diversa por su calidad y circunstancias de la verdadera calamina. Sirve ésta para dar al cobre el color amarillo que tiene cuando le hacen latón.

Calcedonio $=$ Es una piedra dura, medio trasparente. Venía antiguamente de las Indias Orientales. Si su color es de una mezcla graciosa de azul celeste y encarnado, es preciosísima. Se encuentra esta abundancia en Bohemia, Klepia y en las minas de Sajonia ímitanle con el vidrio perfectamente que parece oriental; sirven para grabar sellos, hacer anillos, botoncitos de puños, \&, porque se dejan labrar fácilmente.

Calcinación $=$ La operación de calcinar.

Calcinación furiosa $=$ Es una operación en la cual se funde la materia mediante el fuego y se mantiene fundida hasta que se reduce a cal. Se hace poniendo la materia a fundir en vaso conveniente, y después se menea para que sus partes se desunan como en la pulverización del plomo y estaño.

Calcinación linitoria $=$ Es una reducción en polvos de las materias duras y metálicas mediante la corroción de algún licor con que se humedecen.

Calcinar $=$ Es dividir los cuerpos maduros y de más sólida reunión en partículas y polvos, mediante el calor o los monstruos salinos.

Calcitis $=$ Es una tierra vitriólica de monte que da una tinta roja y tambien se halla blanca conforme a la calidad del terreno del monte.

Calda $=$ Llaman los herreros a cada vez que entran en hierro en la fragua para calentarlo, a fin de trabajar en ello.

Caldera $=$ La parte inferior del torno que se esta escavando.

Caldera de la bomba $=$ Sin definición.

Calentadura (V. Calda).

Calichal $=$ Es una cosa blanca que está incorporada con el metal negrillo a modo de cal amasada $\mathrm{y}$, ordinariamente, donde éste se cría hay metales negrillos y de otras suertes.

Calentadura $=$ La primera plancha que se beneficia en el horno de fundición..

Calzo $=$ Es el conjunto de cinco camones de carro o carreta.

Caminos $=$ Llámanse así en algunas partes los costales o las zacas del metal.

Camón= Uno de los cinco trozos de madera que pone en la circunferencia de las ruedas de los carros o carretas; cinco camones juntos forman un calzo.

Campana $=$ Se dice así cuando en la mina se escava de abajo a arriba o a testero, formando la fi- 
gura parecida a una campana, es decir, con más estensión al principio que después que va disminuyendo hasta que por último concluye en corta estensión.

Canal= Reguera que forma en el principio de las galerías a un lado para dar curso a las aguas.

Canales $=$ Especie de caces [sic] que se hacen para conducir por ellos las aguas a las máquinas y malacates que se mueven por agua.

Canalón $=$ Canal de madera de ojadelata, $\&$.

Canaleta $=$ Es un camino por donde corren las lamas y relaves de las conchas en el beneficio de los metales. Suelen ponerse en ella unos cañamazos con sus escaloncillos para que se detenga la pella y azogue que no se vaya a la cocha de los relaves, gajes de las señoras injenieras o mineras.

Canaleta $=$ Caja por donde cae el agua a la tina para beneficiar los metales.

Candado $=$ Sin definición .

Candelero $=$ Úsase en el beneficio de los metales. Es de hechura de 1/2 mort [sic] delgado, y las paredes huecas; por la parte ancha carga sobre los travesaños del cañón, y por la angosta sustenta el platillo que carga la peña.

Candil de mina $=$ Sin definición.

Canecillos $=$ Sin definición.

Canelador $=$ Sin definición.

Canelón $=$ Es un madero que se pone a lo largo en los socabones y cañas cuando el piso y cielo no están muy seguros para colocar sobre ellos los estemples y sostener el cielo.

Canes $=$ Sin definición .

Cantera= Escavación que se hace en la superficie a cielo descubierto con el fin de sacar piedra o formar estanque para reunir aguas, \&.

Canto $=$ Sin definición.

Cantonera $=$ Sin definición.

Caña= Escavación horizontal cuya boca está en lo interior y no en la superficie. Ábrense con el objeto de comunicar unos trabajos con otros con el de solo sacar mineral, \&, cuyos pasadillos o callejones subterráneos sirven para hacer el trabajo de las minas.

Caña de comunicación $=$ La que tiene por objeto el comunicar unos puntos con otros en las minas.

Caña de disfrute $=$ La que se escava con el fin de sacar de ella el fruto que pueda haber en su estensión.

Caña de registro $=$ Cuando se trabaja con el fin de registrar algun sitio o con el buscar filón, vena o trabajos antiguos.

Cañamazo de esprimir $=$ Es un cotense pendiente de un colgadero que se usa en el beneficio de los metales y dentro está la sabanilla y por ambos lienzos se esprime la pella. 
Caño de barro= $=($ V. Aludel $)$.

Cañón= El que se usa en el beneficio de los metales es de barro a modo de atabar grande, algo ancho de boca, con sus bordes y pendientes de ellos se pone en la desazogadera ras con el suelo de la hornilla. Tiene en la boca 4 travesaños gruesos por la parte de dentro donde descansa el candelero que sustenta la puña, y en esta boca encaja la caperuza.

Cañonaje $=$ Sin definición.

Cañones $=(V$. caña $)$

Capa $=$ Palo tendido sobre los peones para formar la portada sobre que se encajan por una entalladura que se llama trasdós.

Caparrosa $=(\mathrm{V}$. vitriolo).

Capellium $=($ V. Capillo $)$.

Caperuza $=$ Es un instrumento de barro delgado que sirve y es beneficio de los metales del alto de 3 cuartos o poco menos a modo de atanor, pero cubierto por lo angosto, y por lo ancho encaja con el cañón; y porque en ella se tapa la piña se llama caperuza.

Capillo= Es un vaso de barro muy delgado en forma de mortero, aunque más ancho de boca en el cual se derrite el plomo o el estaño para, junto con el azogue, echarlo en los cajones cuando lo necesitan.

Cárcel= Endedura que se forma en la cabeza de la bomba para salir el agua por el canalar.

Cárcel $=(\mathrm{V}$. Holambre $)$.

Cargar las carretas $=$ Se hace en Almadén por medio de un maquinillo o cabria, colocando en cada una dos soleras con peso de 521/2@ cada una. Las 50 de mineral, y las $21 / 2$ restantes del peso de la solera. Se pesan antes de cargarlas en los carros que desde allí las conducen por un llano carril al cerco de fundición.

Cargar la bomba $=$ Se dice en Almadén, cuando a la que hay de vapor para sacar las aguas se le pone el monte en la cadera y se le da fuego para ponerla en movimiento.

Cargar los barrenos $=$ Es ponerlos la pólvora bien atacada que necesitan para que despidan piedra. Esta operación se hace entrando ante todas cosas la aguja en el barreno, después echándole la pólvora que suele ser 2 onzas para cada uno de $13 \mathrm{pl}$ atacándola con boliches de arcilla a toda fuerza con la atacadura que sirve a este fin, todo esto sin sacar la aguja hasta que esté perfectamente atacado; en cuyo agujero se entra una la punta delgada de la mecha con una pajuela pegada en el otro estremo a la cual se prende fuego y se dispara el barreno.

Cargo de mineral=En Almadén se llama así a cada $20 @$ de mineral que se echa a los hornos de fundición.

Carpintería $=$ Sin definición.

Carpintero $=$ Sin definición.

Carrear $=$ Es trabajar con los carros de mano, esto es, conducir mineral o zafra de un sitio a otro de la mina. 
Carreros $=$ Los que tiene el oficio o se ejerzitan en carrear.

Carros de mulas $=$ Especie de carreta pequeña de 2 ruedas tirada por una sola mula, en forma de cajón, y sirven en Almadén para conducir leña, agua carbon, \&, de unas oficinas a otras.

Carros de mano= En Almadén, especie de parigüelas que tienen una rueda en un estremo en medio de los dos largueros, sobre las que se cargan los esportones llenos de tierra, piedra, \&, que los mueve un solo hombre o mucha [sic], agarrándose a los estremos opuestos de los largueros y haciendo rodar al carro empujándole para adelante.

Cartabón $=$ Sin definición .

Cascujo $=$ Zafra mala de todas clases.

Casquillo $=$ Sin definición.

Cata $=$ Escavación o mina de poca hondura y estensión.

Catar $=$ Hacer catas.

Catinos $=$ Sin definición .

Cazumbrado $=$ Part. Pas. de cazumbrar.

Cazumbrar $=$ El acto de enrasar el alarife con mezcla, piedra, ladrillo \&, los intermedios o clavos de los pies de pares aguilones o vigas carreras y otras armaduras.

Cavadera $=$ Sin definición.

Cavador $=$ El que cava.

Cazumbros $=$ Los rellenos de intermedios de arcos.

Cebar $=$ Fundir metal en el horno de afinación, añadir nuevo metal al que está en el horno y también reemplazar el metal que se saca del horno con otro nuevo.

Cebar las mechas $=$ Es llenarlas de polvora para que se prendan con más facilidad y prontitud

$\mathbf{C e b o}=$ La pólvora que se introduce en la mecha para cebarla.

Cedazo $=$ Cajón que se compone de un aro redondo de otra figura y una tela de hilo de alambre y sirve para cerner el polvo del mineral o separar las partículas más menudas de aquellas que no lo son.

Cendra $=$ Ceniza amasada con agua que, en Almadén, se emplea para tapar las uniones de los caños en los hornos de fundición y demás respiraderos por donde pueda salirse el vapor.

Cendrada $=($ V. Cendra $)$

Cendrada $=$ Fondo del horno de fundición o afinación que se hace de tierra fina y de cenizas de plantas.

Cendradilla $=$ Hornillo o pequeños vasos de afinación para metales ricos.

Cepillar los maderos $=$ Es alisarlos con cepillos de carpintero. 
Cepillode carpintero $=$ Sin definición.

Cepillo de cubos $=$ El que sirve para cepillar los listones de madera de que se forman los cubos.

Cepillo de labrar $=$ Sin definición.

Cernada (V. Cendra).

Cerradura $=$ Sin definición.

Cerrojo $=$ Sin definición.

Cielo= Es la parte superior de una galeria o caña, esto es, la que según estamos de pie cae perpendicular sobre nuestras cabezas.

Cigarreros $=$ Sin definición .

Ciguiñuela $=$ Sin definición.

Cilindro del torno $=$ Sin definición.

Cima de la montaña $=($ V. Cresta de la montaña $)$

Cimbra $=$ Sin definición.

Cimbrado $=$ Sin definición .

Cimbrar $=$ Sin definición.

Cinabrio $=$ Sin definición .

Cincel $=$ Sin definición.

Cinchar $=$ Es poner cinchos a las tinas, cubos, cubas, \&, para asegurarlos y poder hacer uso de ellos.

Cincho $=$ Cerco de hierro con que se guarnecen las estremidades de los usos o ejes de las ruedas y máquinas que se mueven circularmente y que también sirven para asegurar las cubas, cubos, \&.

Cincho de cubatina $=$ Los cinchos que se emplean en la construcción del cubatinas.

Cincho de cuba $=$ Los que sirven para construir o asegurar todos los listones de que se componen las cubas.

Cintero= Soga de cáñamo de 2 pulgadas á $21 / 2$ de grueso compuesto de 3 fuertes liñuelos, y sirven para sacar de la mina los cargos de mineral y para introducir materiales.

Círculo horario= Aquel que tiene la brújula en el que está hecha la división y graduación de los grados, horas, y minutos.

Círculo repetidor $=\mathrm{Sin}$ definición.

Civica $=$ Sin definición .

Civicon $=$ Sin definición.

Clamar $=$ Sin definición. 
Clave del $\operatorname{arco}=$ Sin definición.

Clavera $=$ Sin definición.

Clavo $=$ Sin definición.

Clavo de galera $=$ Sin definición .

Clavo garabis $=$ Sin definición.

Clavo saetín $=$ Sin definición.

Clavo de espetón $=$ Sin definición.

Clavo gemal $=$ Sin definición.

Clavo bellote $=($ V. Clavo de espetón $)$.

Clavo palmar $=\mathrm{El}$ que tiene un palmo o unas 9 pulgadas de largo con medio dedo de grueso hacia su cabeza y disminuyendo hasta concluir en punta.

Clavo tercial $=\mathrm{El}$ que de largo tiene un pie o 12 pulgadas con el grueso correspondiente.

Clavo [pesiero] $=$ Sin definición.

Clérigos $=$ Las ordenanzas de Yndias tienen por indecente que los frailes y curas se ocupen en beneficiar minas, y más si tienen a su cargo doctrinas de Yndios, por el escándalo y mal ejemplo que resulta de ello; y por causa de la codicia, crueldades y vejaciones que se esperimentan en el manejo de las minas. Sin embargo las leyes de Yndias y el Concilio Mejicano lo permiten a los curas bajo algunas condiciones que no dejan tener alguna violencia en las aplicaciones que las han dado, y algunos apoyos metafísicos en sus ampliaciones. En todo caso ellos están sujetos a las cargas reales de las minas que benefician como es el $5^{\circ}$ y diezmo como los demás vasallos.

Cobertizo $=$ Sin definición.

Cobija $=$ Sin definición.

Cocha $=$ Es un sitio donde se recojen las lamas que salen de la tina en el beneficio de los metales $\mathrm{y}$ aquel donde entran los relaves y donde se hacen y lavan los ensayos menores.

Cochura $=$ Sin definición.

Cochurero $=$ Sin definición.

Codales $=$ Llámanse así dos piezas iguales de madera de 1/2 de largo, 2 pulgadas de ancho y 5 de grueso que sirven para desatascar. Las hay para otros fines de diversas medidas, pero iguales en longitud.

Codillo= Se llama un hierro curvado que sirve en las máquinas de vombas para sacar el agua de las minas. Tienen la figura de un brazo encodado y, cuando son dos las bombas que mueve la mina, y que el un brazo de la bara se levanta, forma el otro su codillo arriba, y cuando lo contrario lo forma hacia abajo.

Cojo= Es un palo que sirbe de trabieso alrededor por la parte interna del torno; 
Coladero $=$ Sin definición.

Colar $=$ Sin definición.

Colen $=$ Sin definición.

Colgadero $=$ Es un palo que está a modo de viga de lagón dentro de la pared, y otra punta cargada sobre un palo con su muesca y de él pende el cañamazo,y debajo está la tina donde cae el azogue esprimido para beneficiar el metal.

Colindantes $=$ Sin definición.

Coloear mamban $=$ Sin definición.

Colores $=$ Los que tiene la superficie de la tierra y se manifiestan al rayo del sol, bermellón, amarillos, u otros que signos de minerales [sic].

Columna de mineral $=$ Sin definición.

Comerse los pilares $=$ Derribar, descarnar, debilitar las fuerzas, pilares o testeros de las minas.

Compañía de América= Es una asociación de diferentes personas que, en vista del honesto y justo lucro que es frecuente y regular en la labor de las minas por las riquezas que ofrecen, se unen para beneficiarlas; porque no siempre el descubridor o $1^{\text {er }}$ dueño de ellas tiene suficiente caudal para poder sufrir los costos de sus trabajos. Fórmanse, pues, estas compañías para que a espensas comunes de los socios que las componen la trabajan, pueblan y disfrutan sus productos, observando para su gobierno lo que prescriben las leyes y ordenanzas de Yndias.

Compañía de mineros= Fórmanse en Alemania, América y otros países de Europa para emprender el trabajo de las minas,

Compañía de aviadores= Esta compañía la propuso un particular de Méjico y aprovó el consejo para las minas de Nueva España. Sin embargo el Virey [sic] informado ser moralmente imposible su permanencia fundiéndose en el informe de dos sujetos cuyo dictamen fue tenido por sospechoso, con cuyo motivo se nombró una junta en Méjico que, examinando las condiciones, reparos y reflexiones, la conveniencia y utilidad que ella causaría, la dio por buena; con todo no tuvo efecto su establecimiento por las causas que espone Gamboa en sus comentarios capítulo VII $\S 9, n^{\circ} 100$.

Compás pendiente $=$ Sin definición.

Compás tendido $=$ Sin definición.

Compuerta $=$ Sin definición.

Comunicar viento $=$ Sin definición .

Conchas $=$ Sin definición.

Congrieles $=$ Son dos piezas parelas de madera con diferentes barrenos agujeros para poner un pasador de una otra y con una escopladura en la misma forma, a fin de que entren dos cuñas encontradas de menor a mayor para comprimir tableros también los hay de fierro para el mismo fin.

Contracaña $=$ Es la comunicación de 2 o mas cañas que se hacen por medio de otra tercera caña con el fin de estender la ventilación o con el de abrir paso para los trabajadores. 
Contramina $=$ Comunicación de dos o mas minas para limpiarlas, estraer los desmontes y sacar los metales (V. socabón)

Contrapunta $=$ Es un madero del grueso y tamaño que requiere la obra a que ha de servir. En las bombas sirve para sostener la cabeza desde un hastial hasta el otro. Sirve con los estemples, cuando por el mucho ancho del parage es menester fortalecerle, y entonces se le pone una contrapunta en medio o en la parte donde tiene menos fuerza y está más endeble. Sirve en los estremos superiores o cabezas de los bantrotes de un torno para que se mantengan firmes en una misma situación. Se emplean también las contrapuntas en cualquiera compostura o reparo que se presenta como vg un entre-costado para afirmar los palos mientras se compone y se deja perfecto en mismo entrecostado. También sirven para afianzar cualquier madero que empieza a aflojar y hacer sentimiento, y darle fortaleza para que se mantenga y aguante como los demás maderos. Por último sirve cuando conviene sentar algún palo de mucho tamaño para sostenerle mientras que ee enderezan, sientan y afirman en el sitio donde es menester dejarle.

Contrata de minas $=$ Se llama en Almadén a la operación de subastar algún sitio con el fin de escavarle, obligándose a ello por tanto o cuanto la vara cúbica.

Contratado= En Almadén, el que contrata tiene por oficio el tomar por ajuste los sitios de la mina para escavarlos por su cuenta.

Contratar $=$ Se llama en Almadén subastar algún sitio de la mina para escavarle con la condición de para los contratados o asentistas, tanto o cuanto por cada barreno, y a ellos la Real Hacienda cierta cantidad por cada vara cúbica de escavación.

Coral piedra $=$ Sin definición.

Coral planta $=$ Sin definición.

Cordel de lino= Sirve para medir las minas, le emplean los delineadores cuando quieren levantar algun plano subterráneo y su grueso suele ser algo más delgado que el cañón de una pluma delgada de escribir.

Cordel de látigo= En Almadén, llaman así al que usan los sirvientes con las mulas de su factoría para hacerlas que [ceden hasta] cuando conviene.

Cordelero $=$ El que tiene por oficio el fabricar cordeles sogas, cinteros y maromillos, las más veces de cáñamo.

Coronillas de las montañas $=(\mathrm{V}$. Cima de las montañas $)$.

Corta de madera= La operación que se practica no solo para cortar la madera de los árboles sino también el descortezado suyo para conducirla a las minas y emplearla en ellas.

Cortadura $=$ Sin definición.

Cortafrío $=$ Sin definición.

Cortar pilar $=$ Es terminar el pilar para dar crucero y formar descanso.

Cortar sogas $=$ Es abandonar, desamparar y dejar la mina y sus tiros. 
Corto $=$ Además de toda pieza que no llega o alcanza a la marca o medida necesaria, se da este nombre a la parte de un estemple o madero que por la líneas [sic] formadas entre alguna de sus caras longitudinales y la testa, no llega al ángulo recto.

Cresta del filoón= (V. Cabeza del filón).

Cresta de la montaña $=$ Su lomo o parte más elevada que por lo regular suele ser de roca descubierta.

Crestones $=$ Peñascos formados de metal crudo, quemazones, guijas o peñas superficiales que ha hecho brotar la fuerza de la vena en figura de cresta de gallo que se ve a mucha distancia.

Creta $=$ Sin definición.

Criadero= Especie de bolsa o bóveda en que el metal esta suelto; llámase también bohedal.

Cristal de roca $=$ Sin definición.

Cristalización $=$ Sin definición.

Cristalografía $=$ Sin definición.

Criva $=$ Cajón redondo o cuadrangular cuyo fondo suele ser de cuero con muchos agujeros o de un tejido o red de alambre y también de cordel. Las hay pequeñas que un hombre solo las maneja y grandes que se necesitan dos según el uso a que se destinan. Sirven para cerner cal, tierra, \&, para separar las partes gruesas de las menudas. Los agujeros de unas son más pequeños que los de otras según que se quiera sacar el cernido más o menos delicado.

Crivón $=$ Se da este nombre a las crivas cuando son muy grandes.

Crucero= Llámase crucero en las minas al parage donde una caña corta a otra.

Cuadrilla de bombas = En Almadén, se llama al número de bomberos que están juntos en una entrada de mina para tirar de las bombas de mano que en sus minas existen.

Cuartear un contrato $=$ Se llama en Almadén cuando habiéndose quedado un asentista con cierta obra por ajuste, le rebaja otro dentro del tiempo prefijado (ó de 3 dias) la $4^{\text {a }}$ parte de su remate, y entonces se pone en nueva subasta la obra para ver si hay algún otro postor que haga aún mejor partido; y si no se queda por cuenta del cuarteante.

Cuarteo $=$ El acto de cuartear.

Cuarto de herramientas $=$ En Almadén, hay dos en lo interior de la mina, uno en el $6^{\circ}$ piso y otro en el $8^{\circ}$, y tienen por objeto guardar allí la herramienta para cuando los destajeros, operarios, $\&$, van a trabajar;

Cuartón de pino $=$ Sin definición.

Cuba $=$ Sin definición.

Cuba de mano $=$ Sin definición.

Cubatina $=$ Sin definición.

Cఊ= Sin definición. 
Cubillo= Es un casquillo de hierro que se pone en las huidas que se hacen en la piedra para entrar las muñecuelas de los paletones que se ponen en los husos o en los ejes de las ruedas que mueven las máquinas de las minas.

Cucharilla $=$ Instrumento compuesto de un hierro delgado y del largo de 16 a 18 pulgadas con un labio o especie de doblez o ángulo recto con el largo, y sirve a los mineros destajeros para sacar el polvo del barreno cuando le están abriendo.

Cucharón= Es una artesa o artesón que recibe las aguas de una bomba o la que arrojan o vierten los arcaduces de una noria o otra máquina hidráulica.

Cuchillas $=$ Sin definición.

Cueba $=$ Sin definición.

Cuerda $=$ Cordelillo torcido de cáñamo de diferentes longitudes para la formación de algunos trazos, direcciones y medidas. Úsanla los mineros para colgar la brújula y semicírculo.

Cuña= Una pieza de hierro como de 3 a 3 1/2 de peso de 5 superficies planas y que acaba en una línea o filo en el estremo opuesto a su cabeza. Sirve para introducirla por las juntas de las rocas a golpe de porra y quebrantar de este modo la piedra.

Cuño= Sin definición.

Cuñón principal $=$ Cabeza de la bomba

Curva $=$ Sin definición.

Curvatura $=$ Sin definición .

$\mathbf{C u x}=$ Porción de concesión de mina hecha a un particular.

Cajas a cola de milano $=$ Cuando se trata de ensamblar una riestra o peinazo por la cara esterior de un madero, embutiendo en él una punta de dicho peinazo con el fin de que sin cuña alguna no pueda escapar de tal caja, porque se le da figura de dicha cola por ser más ancha de fuera que de adentro, esto es, de figura trapecia.

\section{CH}

Chaflán $=$ Sin definición.

Chaleites $=$ Sin definición.

Chapa $=$ Sin definición.

Chancar $=$ Es quebrantar algo el mineral que se quiere beneficiar y dejarle así a medio moler.

Chapa de zaca $=$ Sin definición.

Chapado $=$ Sin definición.

Charqueo interior $=$ La limpieza de piletas o charcas de agua por canales para dirigirlas al tiro.

Chaveta $=$ Sin definición.

Chalonites $=(\mathrm{V}$. Bufonites $)$ 
Chiflón (Trabajar a) = Se dice cuando a un tiempo se gana en la mina longitud y profundidad .

Chiflón= Es un cañón de madera por donde cae el agua al lavadero para beneficiar los metales.

Cimenea [sic] del atizadero $=$ Sin definición.

Chimenea de las camaretas $=$ Sin definición.

China $=$ Sin definición.

Chingar $=$ Es perderse o desaparecerse alguna cosa, como cuando en una mina estermina el filón o filones, \&, \&.

Chupalla = Es una medida de que se usa en América para el azogue cuando se vende por menudo.

Chupón de la bomba $=$ Sin definición.

D

Dado= Es donde el mazo da el golpe para moler el metal que se trata de beneficiar.

Dar crucero $=$ Es trabajar horizontalmente a lo largo o ancho de la veta para dar viento a las labores o evitar una dureza invencible o ir a buscar la veta que se llama también cañón. Se cruza por la labor principal que se lleva por el pozo en las vetas paradas, o por el frontón en las tendidas.

Dar estacas $=$ Sin definición.

Debanar el aire $=$ Sin definición.

Delineación $=$ Es la operación de delinear.

Delineador de minas $=$ Minero facultativo cuya obligación es describir sobre el papel la situación y estado de una mina con las operaciones practicadas de antemano en lo interior con los instrumentos aparentes, fijando la posición de los socabones, tornos, \&, También es de su obligación fijar en la superficie los puntos correspondientes a otros de lo interior, determinar los rumbos principales de la dirección de las venas; verificar rompimientos para comunicar unos trabajos con otros, \&, \&. En una palabra es de su deber practicar los probs. [sic] correspondientes a la geometría subterránea.

Delinear $=$ Sin definición.

Demasías de minas $=$ En América es el terreno no ocupado que yace libre entre dos minas medidas y ocupadas y puede darse al $1^{\circ}$ que le pide, aunque no puede ser al minero que se ha mejorado en mina inmediata por haber el dejado las demasías; y que sería esto dejar una cosa y retenerla al mismo tiempo, y dar a un minero mas varas de mina que permite la ley.

Demoler $=$ Sin definición.

Denunciación $=($ V. Denuncio $)$.

Denunciador de minas $=$ El que denuncia una mina. Este sucede al anterior poseedor por el denuncio que hizo de ella y por la posesión que se le dio y que el otro perdió; porque la ley que le desposeyó le considera como que en él se acaba el registro de aquella mina de que hace cesión al denunciador, el cual empieza con nuevo registro a poseerla como si antes de él nadie la hubiese tenido en su propiedad. 
Denunciar mina= Es en América declarar ante la Justicia y hacer enregistrar una mina por despoblada o abandonada y, en tal caso, se da por valdío de commiso y por perdida, aunque tenga dueño y puede el denunciado pedir la posesión de ella con las condiciones que prescribe la ley y las ordenanzas.

Denuncio $=$ Declarar de haber quedado despoblado una mina por más de cuatrimestre para que se declare el aprovechamiento al denunciador.

Derecera $=$ Sin definición .

Derechos Reales $=$ Los que pagaron antiguamente los mineros del producto de las minas han sido diversos, como $2 / 3,4^{\mathrm{a}} 5^{\mathrm{a}}$, quintavo, diezmo $\&$ hasta que quedó en el quinto; y el diezmo $6^{\circ}$ los rescatadores y mineros. Estos derechos no se cubrían siempre con tal rigor en vista de lo imcosteables que son algunas minas en la Nueva España. Generalmente se pagaba al Rey el diezmo de todos los metales, bajillas, \&, deduciendo antes el uno por \% del ensayador, fundidor, marcador, \&, que en su defecto queda por de commiso.

Derrocar bancos $=$ Es demolerlos para sacar el mineral bien por medio de barrenos o bien con pico, \&, según sea la calidad de la piedra, pero lo más constante es lo $1^{\circ}$.

Derrumbamiento $=(\mathrm{V}$. Derrumbe $)$.

Derrumbe $=$ La ruina de las minas undiéndose su cielo y labores por falta de firmeza.

Desaguar la mina= Es sacar con bombas o tiros el agua de las minas o planes de ellas a la superficie para poder seguir trabajando en sus labores.

Desagüe $=$ La operación de desaguar las minas.

Dasalabear $=$ Es quitar a las tablas o maderos el pandeo o alabeo que tengan.

Desamparar la mina $=$ Es como abandonarla por falta de fruto.

Desaplomar $=$ Sin definición.

Desaplome $=$ Sin definición.

Desatierres $=$ Es lo mismo que desmontes de que hablan las ordenanzas, que no se pueden cargar los desatierres de una mina sobre terrero de mina ajena, ni se pueden dejar dentro de las minas que siempre deben estar limpias y dembarazadas, sin especial permiso de la Justicia, que debe reconocer si el hueco en que los echan dentro de las minas es inútil y sin poder causar perjuicio y al mismo tiempo si pueden servir a reparos y evitar con ellos algunos hundidos o derrumbes de las minas. Voz amer.

Desazogadera $=$ Es el lugar donde se desazogan las piñas o donde se les saca el azogue que contienen.

Desazogar $=$ En el beneficio de la plata y oro por amalgamación es quitar a las piñas el azogue que contienen.

Desbocarse la barrena $=$ Es cuando por mal templada salta el acero de su boca al dar los golpes para abrir barreno. 
Desbocarse el martillo= Es cuando salta algún poco de acero de su boca.

Descalzar $=$ Es un trabajo que se hace en las minas y consiste en abrir un paso en la piedra del piso de las cañas entre la veta y los lienzo o hastiales a lo largo; porque como no es fácil romper todo de una vez para darle la anchura que se quiere tenga la obra; se empieza de esta madera por las orillas en los costados de la vena. Sin embargo, no se ha de dar más ancho a esta obra que cuanto sea necesario para que un hombre estrechamente pueda moverse en ella, esto es estendiendo los codos. Es de notar que esta maniobra solo se hace donde lo permite la piedra que corre seguidamente y no donde la piedra está juntada en remolino; pues entonces pues entonces [sic] se labra esta parte donde se proporciona la calidad de la roca.

Descansillo $=$ Es en las minas que se baja y sube por escaleras de mano una especie de parada de fuertes tablas, donde se descansa, y es donde concluye una escalera y principia otra.

Descargar las carretas $=$ Es apear de ellas las soleras de mineral que en Almadén conducen desde la boca del pozo principal al arco de fundición.

Descargar la bomba $=$ Sin definición .

Descargar el horno de fundición= En Almadén, sacar después de verificada la destilación destilación [sic] del azogue, la escoria que haya resultado dentro.

Descargue $=$ La última plancha que se beneficia en en $[$ sic]el horno de la fundición que es la mayor.

Desclavador $=$ Sin definición.

Desclavazón $=$ Sin definición.

Desclaves $=$ Sin definición.

Desgraciarse el metal $=$ Sin definición.

Deslamar $=$ Es cuando se echa el metal que se ha de beneficiar en la tina, y comienza el molinillo a andar poco a poco y a salir el agua por encima de la tina, que es la lama.

Desmonte $=$ La piedra inútil que se quita de los lados de la veta, que queda limpia separándose las zafras y piedras.

Despalmar $=$ Sin definición.

Despalme $=$ Sin definición .

Despensa $=$ Cuarto con seguridad para custodiar los metales ricos.

Despilar $=$ Quitar o echar abajo los pilares en las minas.

Despilaramiento $=$ La operación o trabajo de despilar.

Despoblar $=$ Desamparar o abandonar una mina sin entretenerla con los operarios establecidos.

Destajero $=$ El trabajador que en las minas se invierte en hacer barrenos.

Destajo $=$ El oficio del destajero. 
Destilación $=$ Sin definición

Destiladero $=$ Sin definición .

Destilar el azogue $=$ Sin definición .

Destornillador $=$ Sin definición.

Destornillar $=$ Sin definición.

Destravar $=$ Sin definición.

Desviar $=$ Sin definición.

Día de medidas = Llámase así en Almaden el último sábado de cada mes, que se emplea por el Director y Oficiales en medir las escavaciones qe se han hecho durante el mes.

Dibujar $=$ Sin definición.

Dibujo $=$ Sin definición.

Dibujo de tanteo (V. de figura).

Dibujo de figura $=$ Sin definición.

Dibujo geométrico= Sin definición.

Dibujo de perspectiva $=$ Sin definición.

Distribuidores $=$ Los que tienen en los establecimientos de minas el encargo de distribuir las herramientas y llevar cuenta de los sujetos que las reciben, si las entregan o si tienen que devolveras [sic], \&.

Distribuidor de pólvora (fiel)= En Almadén, se llama al dependiente que tiene la obligación de distribuir a los asentistas de sitios la pólvora y pajuelas que necesitan y llevar cuenta exacta de todo.

División del torno $=$ Sin definición.

Docimasia $=$ Sin definición.

Dobela $=$ Sin definición.

Doga $=($ V. Dobela $)$.

Cartucho $=$ Sin definición.

Cepo $=$ Sin definición.

Cincelar $=$ Sin definición.

Contra armilla $=$ Sin definición.

Chavetear $=$ Sin definición.

Dentar $=$ Sin definición.

Dentellado $=$ Sin definición.

Dentenallas $=$ Sin definición . 
Desazolbado $=$ Sin definición .

Desazolbarse $=$ Sin definición .

Embarlotar $=$ Sin definición .

Embarlote $=$ Sin definición.

Emparejos $=$ Sin definición.

Enarmillar $=$ Sin definición.

Espiga $=$ Sin definición.

Esquijerar $=$ Sin definición.

Faldeo $=$ Sin definición.

Fijas $=$ Sin definición.

Junterilla de traslapar $=$ Sin definición.

\section{$\mathbf{E}$}

Echadero= Plano sobre el arco para cargar las mulas, tender, limpiar, pesar, $\&$, los metales.

Echado $=$ Lo mismo que recostado, inclinación de las venas sobre uno u otro lado.

Efervescencia $=$ Sin definición.

$\mathbf{E j} \mathbf{j}=$ En los ingenios de beneficio de metales, es una viga gruesa que hace mover la viga de ingenio, y por parte de adentro hace subir y bajar los mazos con las levas que están asidas al mismo eje.

Ejión $=$ Sin definición.

Ematites $=$ Sin definición .

Embalse $=$ Sin definición.

Embasijar $=$ Sin definición.

Émbolo $=$ Sin definición.

Emborrascarse la mina $=$ Perderse la vena o encontrar gija [sic] en vez de metal.

Embudo de canales $=$ Sin definición.

Empacar $=$ Se llama así en Almadén a la maniobra de embasijar el azogue en frascos de fierro o a falta de éstos en unos valdeses.

Empalmar $=$ En las minas se dice cuando por casualidad no alcanza un solo palo de los que se han de colocar en los brocales de los pozos, escaleras, $\&$, hay que añadir uno o más.

Empalme $=$ La operación de empalmar.

Empaque $=$ El ejercicio de empacar.

Empentar $=$ Sin definición. 
Emplanchar $=$ Sin definición.

Empujar $=$ Sin definición.

Empuge $=$ Sin definición.

Enarbolar $=$ Sin definición.

Encadenado $=$ Sin definición.

Encadenar $=$ Sin definición.

Encajamiento $=$ Sin definición .

Encamación $=$ Sin definición.

Encamador $=$ Sin definición.

Encamar $=$ Sin definición.

Encapada $=$ Se llamada [sic] cuando una mina va encubierta y no se ve señal de metal por cima de cerro.

Enchidor $=$ El que inche.

Enchir $=$ Es lo mismo que llenar los esportones de tierra, zafra, metal, \&.

Encojado $=$ Sin definición.

Encomendero $=$ Sin definición .

Encorbado $=$ Sin definición.

Encostillados $=$ Son palos derechos que se ponen paralelamente en los tornos uno contra otro desde un bantrote a otro, a fin de asegurar los lienzos o hastiales, mayormente en las pendientes, aunque suelen tambien emplearse para el yacente y a veces en los testeros.

Encostillar $=$ Es sostener de pie derecho los encostillados que van paralelos a lo largo de un bantrote a otro.

Endejas $=$ Sin definición.

Enderezar $=$ Sin definición.

Enfrascar $=$ Es lo mismo que empacar azogue en solo frascos y no valdeses.

Engarabatador $=$ El trabajador que se emplea en las minas en engarabatar.

Engarabatar $=$ Es asegurar en las minas al cintero los cubos, esportones, tinas, \&, que se han llenado de mineral, solera, zafra, agua, \&, para sacarlos con el huso o con la garrucha y cintero fuera de la mina por el pozo.

Enjugar $=$ Sin definición.

Enjutas $=$ Sin definición.

Enlatonado $=$ Sin definición. 
Enlatonar $=$ Sin definición.

Enlodar el barreno= Es enjugarle con polvo de boliches de arcilla cuando destila agua o humedad para que cuando se cargue no impida ésta a la inflamación de la pólvora.

Enmaderación $=(V$. Entivación $)$

Enmaderar $=(V$. Entivar $)$

Enrás $=$ Sin definición.

Enrasar $=$ Sin definición.

Enrejar $=$ Sin definición.

Ensamblado $=$ Sin definición .

Ensambladura $=$ Sin definición .

Ensamblamiento $=$ Sin definición .

Ensamble $=$ Sin definición .

Ensanche $=$ Sin definición .

Ensaye $=$ Esperimento que se hace por fuego o azogue en corta cantidad de metal para saber su ley y si puede costear su beneficio.

Entablar $=$ Sin definición.

Entalonado $=$ Sin definición.

Entalonar $=$ Sin definición.

Entalladura $=$ Sin definición.

Entarimado $=$ Sin definición.

Entarimar $=$ Sin definición.

Entehallas $=$ Sin definición.

Enterizo $=$ Sin definición.

Entivación $=$ Es el trabajo de entivar.

Entivar $=$ Es fortificar las minas con maderas para que no se resientan sus astiales ni testero.

Escalera= Madero redondo, grueso de 8, 10 y más varas de largo, con muescas que sirven de escalones para subir por los pozos y tornos y los descansillos de una a otra sirven para poder subir y bajar los operarios sin impedirse.

Escalera $=$ Fragmento tachado

Escalera $=$ Es por donde suben y bajan las gentes en las minas por el torno o pozo. Compónese de dos medios tirantes paralelo serrados a lo largo, de longitud de 6, 8, 10, \&, varas que se llaman largueros, labrados en forma cuadrilonga que tienen regularmente 5 o 6 pulgadas de ancho y unas 4 de grueso, y distantes entre sí como cosa de $1 / 2$ vara. En éstos se abren unas holambres, y también 
cárceles (según sea la escalera holambrada o boticaria) a a [sic] la distancia de una tercia, en que se ajustan los escalones y se aseguran en los largeros [sic] muchas veces con cuñas que los atraviesan, y otras con clavos jemales.

Escalera holambrada $=$ Es la que en los largueros tiene holambres para entrar los escalones. Se colocan en los sitios donde padecen poco porque para un escalón nuevo que haya que echarles hay que desbaratarla toda, lo que no sucede con las boticarias.

Escalera boticaria $=$ La que en vez de tener holambres en los largueros como las holambradas para que entren los escalones, tiene unas cárceles que sirven al efecto. Éstas se emplean en las minas en los sitios donde más pronto se rompen o están espuestas a los barrenos, porque sin necesidad de deshacerlas se pueden componer echando cuando escalones nuevos se quieran; no sucede así con las de holambre por lo que son las de que se trata de más frecuente uso.

Escalones $=$ Son unos palos tableados como de $1 / 2$ vara de largos y del grueso de 2 a 3 pulgadas con mayor ancho en el el [sic] medio que en sus estremos a la manera de una costilla de silla. Se aseguran en los largueros de las escaleras metiéndolos en los holambres o encajándolos en las cárceles, según la clase de la escalera.

Escapulario $=$ Sin definición.

Escarpar $=$ Sin definición.

Escarpia $=($ V. Alcayata $)$

Escarbadera $=$ Sin definición.

Escavación $=$ Sin definición.

Escavación a caña $=$ Sin definición.

Escavación a banco $=$ Sin definición .

Escavación a cielo $=(\mathrm{V}$. Escavación a testero $)$

Escavación a testero $=$ Se dice cuando el destajero en pie o de rodillas trabaja en el cielo de la galería o encima de su cabeza en la bóveda de la labor.

Escavación a rebajo $=$ Sin definición.

Escavación al través $=$ Sin definición.

Escavación a ensanche $=$ Sin definición .

Escobilla $=$ Sin definición.

Escoda $=$ Sin definición.

Escofina $=$ Sin definición.

Escole $=$ Sin definición .

Escombros $=$ Sin definición .

Escoplar $=$ Sin definición. 
Escoplar las juntas $=$ Sin definición.

Escoplo $=$ Sin definición.

Escoria $=$ Sin definición.

Escorial $=$ Sin definición.

Escuadra $=$ Sin definición.

Escuadrar $=$ Sin definición.

Espadilla $=$ Cañón que entra en las bombas dentro de la vaina.

Espejuelo $=$ Especie de guija menos consistente que la ordinaria con una tez aceitosa como el talco o semejante al yeso.

Espejuelo de rueda $=$ Sin definición.

Espejuelo de pertiguillo $=$ Sin definición .

Espender $=$ Sin definición.

Espeque $=$ Sin definición.

Espetón $=$ Sin definición.

Espetón de horno $=$ Sin definición .

Espetón de fragua $=$ Sin definición.

Esplotación $=$ Sin definición.

Esplotación $=$ Sin definición.

Esportón $=$ Sin definición.

Esposa $=$ Sin definición.

Espuerta $=$ Sin definición.

Espuma de guija blanca $=$ Sin definición .

Estaca $=$ Sin definición.

Estaca aterrada $=$ Sin definición.

Estaca fija $=$ La boca principal en que se registra la mina, la cual es invariable cuando se mide o mejora de medidas el minero. Llámanse también fijas las que se han dado al vecino.

Estacada $=$ Sin definición.

Estacar $=$ Sin definición.

Estadal $=$ Sin definición.

Estadío $=$ Sin definición .

Estanque $=$ Sin definición. 
Estantales $=$ Puntales o estemples para sostener los hastiales o contrapuntas.

Estantes $=$ Son dos palos en forma de tablones puestos sobre los largueros del brocal del torno en que descansa el huso en una entalladura de figura de semi luna, en que éste da sus vueltas con el cintero, espuerta o cubo para sacar o introducir cualquier cosa en la mina.

Estemple $=$ Es un palo del grueso de más o menos según el servicio de que debe hacer. En los tornos sirven los estemples para entremedios de los bantrotes y se llaman entonces encadenados. En las cañas y planes son pies derechos que sirven para mantener los cielos o testeros. Igualmente sirven tendidos contra los astiales y formando con ellos ángulos, esto es, a saber, estando puestos con la punta en una huida abierta en lo bajo de un hastial o lienzo y apoyándose con el otro estremo, que es la cabeza contra el astial o lienzo opuesto. Esta cabeza si se sostiene desnuda contra el astial es

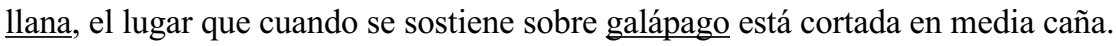

Estemple principal $=$ Sin definición .

Estéril $=$ Sin definición.

Esterilizar $=$ Sin definición.

Estilete $=$ Sin definición.

Estilo $=$ Sin definición.

Estinguir la mina $=$ Sin definición.

Estopado $=$ Sin definición.

Estopar $=$ Sin definición.

Faena $=($ trabajar $a)=$ Sin definición. 